\title{
Breakdown of the Summertime Meridional Teleconnection Pattern over the Western North Pacific and East Asia since the Early 2000s
}

\author{
XINYU LI \\ College of Oceanography, Hohai University, Nanjing, China \\ RIYU LU \\ State Key Laboratory of Numerical Modeling for Atmospheric Sciences and Geophysical Fluid Dynamics, Institute of \\ Atmospheric Physics, Chinese Academy of Sciences, and College of Earth and Planetary Sciences, University of the Chinese \\ Academy of Sciences, Beijing, China
}

(Manuscript received 5 October 2019, in final form 10 June 2020)

\begin{abstract}
The meridional teleconnection over the western North Pacific and East Asia (WNP-EA) plays a predominant role in affecting the interannual variability of East Asian climate in summer. This study identified a breakdown of the meridional teleconnection since the early 2000s. Before the early 2000s, there are close tropical-extratropical relationships in light of both circulation and rainfall anomalies. For instance, the westward extension of the western North Pacific subtropical high (WNPSH) is closely associated with the southward shift of the East Asian westerly jet (EAJ), and more rainfall in the tropical WNP closely corresponds to less rainfall in the subtropical WNP-EA. However, after the early 2000s, the tropical-extratropical relationships are absent. Particularly, the tropical WNP precipitation anomalies can induce WNPSH anomalies, but the WNPSH anomalies cannot induce subtropical precipitation in the latter period, due to the absence of EAJ-related extratropical circulation anomalies. Further results indicate that in the latter period, the westward extension of the WNPSH is associated with the decay of central Pacific-like El Niño, and simultaneous summer sea surface temperature (SST) anomalies in the central eastern Pacific favor the northward shift of the EAJ, resulting in the disruption of the WNPSH-EAJ relationship. This evolution of tropical SSTs is sharply different from the decay of canonical El Niño and simultaneous summer tropical Indian Ocean warming, which favor the WNPSH-EAJ correspondence in the former period.
\end{abstract}

\section{Introduction}

It has been well known that there is a meridional teleconnection over the western North Pacific and East Asia (WNP-EA) during summer (e.g., Nitta 1987; Wang et al. 2001; Lu 2004; Kosaka and Nakamura 2006, 2010; Huang et al. 2012; Gong et al. 2018; X. Li et al. 2019; Sun et al. 2019). This teleconnection is referred to as the Pacific-Japan pattern (Nitta 1987) or East Asia-Pacific pattern (Huang and Sun 1992). It is characterized by the zonally elongated anomalies that appear alternately in the meridional direction over the WNP-EA. These anomalies appear over both the tropical and extratropical regions, with the longitude mainly ranging from $110^{\circ}$ to $160^{\circ} \mathrm{E}$. Therefore, this meridional teleconnection plays a predominant role in linking the tropical forcings,

\footnotetext{
Corresponding author: Dr. Xinyu Li, lixinyu@hhu.edu.cn
}

such as ENSO, and extratropical East Asian climate (Huang and Wu 1989; Lee et al. 2006; Yang et al. 2007; Kim et al. 2009; Sun et al. 2010; Xie et al. 2016; Li et al. 2017).

The establishment of the meridional teleconnection manifests as strong tropical-extratropical connections over the WNP-EA. It is well known that the meridional teleconnection is closely associated with the precipitation or convection anomalies over the tropical WNP (e.g., Nitta 1987; Lau et al. 2000; Wang et al. 2001; Lu and $\mathrm{Lin}$ 2009; $\mathrm{Li}$ and $\mathrm{Lu}$ 2017; H. Li et al. 2019). Suppressed (enhanced) precipitation over the tropical WNP induces a lower-tropospheric anticyclonic (cyclonic) anomaly in the subtropical WNP, which corresponds to the westward extension (eastward retreat) of the WNP subtropical high (WNPSH) in the lower troposphere and the southward (northward) displacement of the East Asian westerly jet (EAJ) in the upper 
troposphere. The anticyclonic (cyclonic) anomaly favors enhanced (suppressed) rainfall over the subtropical East Asian rainband through modifying water vapor transport (Huang and Sun 1992; Wang et al. 2001; Zhou and Yu 2005; Li and Lu 2017, 2018), and the southward (northward) shift of the EAJ is also favorable for enhanced (reduced) subtropical rainfall (Liang and Wang 1998; Lu 2004; Xuan et al. 2011; Li and Zhang 2014; Du et al. 2016; Wang et al. 2018, 2019; Yan et al. 2019). The subtropical rainfall anomalies, as a heat source, can in turn enhance the meridional teleconnection ( $\mathrm{Lu}$ and $\mathrm{Lin}$ 2009; Sun et al. 2010). Therefore, with regard to circulation anomalies, the meridional teleconnection can be illustrated by the correspondence of the westward extension (eastward retreat) of the WNPSH and the southward (northward) shift of the EAJ (Wang et al. 2001; Lu 2004; Lu and Lin 2009; Lin et al. 2010); and with regard to precipitation anomalies, it can be described by a seesaw pattern between the tropical and subtropical WNP-EA precipitation (Lau et al. 2000; Lu 2004; Kwon et al. 2005; Yim et al. 2008a; Kosaka et al. 2011; Li and Lu 2017). The absence of these tropical-extratropical connections suggests the breakdown of the meridional teleconnection, which is the main concern in this study.

The sea surface temperature (SST) anomalies over the tropical central eastern Pacific significantly affect the components of the meridional teleconnection. Particularly, as a strong tropical interannual variability, ENSO plays an important role. During the El Niño peaking winter, an anticyclonic anomaly appears over the subtropical WNP and maintains into the following summer, corresponding to the westward extension of the WNPSH (e.g., Wang et al. 2000; Yang et al. 2007; Xie et al. 2009; Wang et al. 2013; Xie et al. 2016; Jiang et al. 2019). Associated with the decay of El Niño, significant positive SST anomalies appear over the tropical Indian Ocean in the following summer, and play an important role in reinforcing the anticyclonic anomaly (Yang et al. 2007; Xie et al. 2009; Huang et al. 2010; Yun et al. 2013; Xie et al. 2016; Huang et al. 2016; Li et al. 2017). On the other hand, ENSO may exert an influence on the meridional displacement of the EAJ through the meridional teleconnection, or through the SST anomalies over the tropical central eastern Pacific in simultaneous summer (Lin and Lu 2009; Lin 2010; Qu and Huang 2011).

However, the meridional teleconnection, including the associated seesaw pattern in precipitation between the tropical and subtropical WNP, tends to show decadal or interdecadal changes (Wu and Wang 2002; Kwon et al. 2005; Yim et al. 2008a,b; Lin et al. 2010; Kubota et al. 2016; Huang et al. 2018; Xu et al. 2019). In the previous studies, there is a clear diversity in the turning points of decadal changes, such as in the 1970s (Wu and
Wang 2002; Lin et al. 2010) and in the 1990s (Kwon et al. 2005; Yim et al. 2008b; Huang et al. 2018; Xu et al. 2019), mainly due to their different focuses. Furthermore, different possible reasons for the decadal changes are proposed. For example, Wu and Wang (2002) attributed the enhanced tropical-subtropical seesaw pattern in the late 1970s to the change of the location of the tropical WNP convection and Lin et al. (2010) highlighted the role of the easterly shear over the tropical WNP in weakening June meridional teleconnection in the late 1970s. Xu et al. (2019) also suggested that the convection location and easterly shear over the tropical WNP result in the weakened and eastward shifted teleconnection after the late 1990s. Furthermore, some studies discussed the role of ENSO evolution in affecting the components of the teleconnection (Yim et al. 2008b; He and Wu 2018; Huang et al. 2018; Wu and Wang 2019; Huang et al. 2020), but these studies mainly focused on the tropical anomalies rather than the tropical-extratropical couplings. In this study, we would show a comprehensive breakdown of the meridional teleconnection in the early 2000s, focusing on the tropical-extratropical connections, and explore the possible role of tropical SSTs in inducing the breakdown of teleconnection.

The rest of this article is arranged as follows: In section 2, we describe the data and indexes. In section 3, the meridional teleconnection and its decadal change are diagnosed by using the reanalysis data. In this section, we show a breakdown of the WNPSH-EAJ relationship in the early 2000s, and the vague WNPSH-EAJ relationship results in the weakened impact of the WNPSH on subtropical rainfall after the early 2000s, inducing the breakdown of the seesaw pattern in tropical-subtropical rainfall anomalies. Section 4 discusses the role of the tropical SST evolution in the decadal change of the meridional teleconnection. Section 5 provides a summary and discussion.

\section{Data and indexes}

The data used in the present study include the monthly European Centre for Medium-Range Weather Forecasts (ECMWF) interim reanalysis (ERA-Interim; Dee et al. 2011) and the NOAA extended reconstructed SST version 4 (ERSST.v4) data. The horizontal resolution of the ERA-Interim reanalysis data is $1.5^{\circ} \times 1.5^{\circ}$, and that of the SST data is $2.0^{\circ} \times 2.0^{\circ}$. Also used are the precipitation data derived by the Global Precipitation Climatology Project (GPCP; Huffman et al. 1997; Adler et al. 2003). All data are extracted during 1979-2017 and the months of June, July, and August (JJA) are used to represent summer.

In this study, we mainly use the WNPSH-EAJ correspondence and the tropical-subtropical seesaw pattern in precipitation to describe the meridional teleconnection. To 
(a) WNPSHI_UV850 (1979-2017)

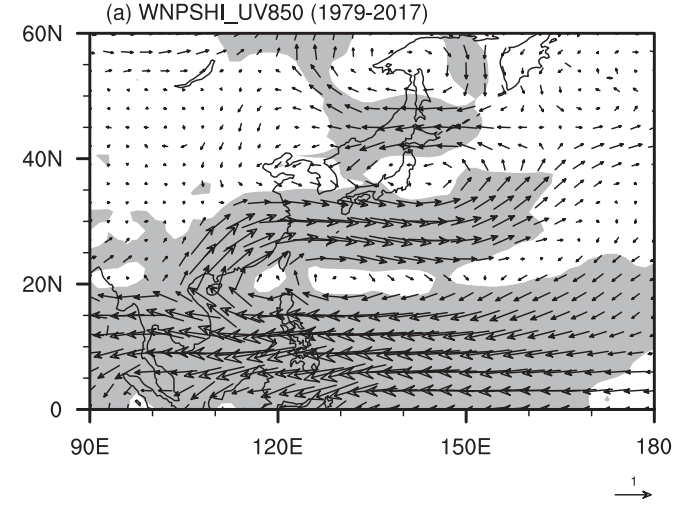

(b) WNPSHI U200 (1979-2017)

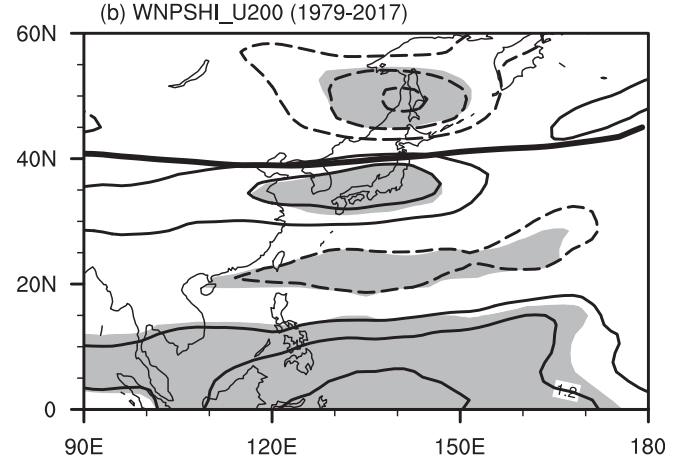

FIG. 1. Regression of (a) 850-hPa horizontal winds (vectors; $\mathrm{m} \mathrm{s}^{-1}$ ) and (b) 200-hPa zonal winds with respect to the normalized WNPSHI during 1979-2017. The bold black line in (b) represents the climatological jet axis during summer and the contour interval is $0.5 \mathrm{~m} \mathrm{~s}^{-1}$. Zero contours are omitted. Shading in (a) indicates that either zonal or meridional wind anomalies are significant at the $95 \%$ confidence level based on Student's $t$ test and in (b) refers to the significant zonal wind anomalies.

facilitate the discussion on the relationship between the interannual variability of the WNPSH and the meridional displacement of the EAJ, the WNPSH index (WNPSHI) defined by Wang et al. (2001) and the EAJ index (EAJI) defined by Lu (2004) are adopted. The WNPSHI is defined as the difference of averaged zonal winds at $850 \mathrm{hPa}$ between $20^{\circ}-30^{\circ} \mathrm{N}, 110^{\circ}-140^{\circ} \mathrm{E}$ and $5^{\circ}-15^{\circ} \mathrm{N}, 100^{\circ}-130^{\circ} \mathrm{E}$. This definition is the same as Wang et al. (2001), but with opposite sign. Therefore, a positive (negative) WNPSHI indicates an anticyclonic (cyclonic) anomaly over the subtropical WNP, and the WNPSH extends westward (retreats eastward). The EAJI is measured by the difference between the $200-\mathrm{hPa}$ zonal winds averaged over $30^{\circ}-40^{\circ} \mathrm{N}, 120^{\circ}-150^{\circ} \mathrm{E}$ and $40^{\circ}-$ $50^{\circ} \mathrm{N}, 120^{\circ}-150^{\circ} \mathrm{E}(\mathrm{Lu} 2004)$. A positive EAJI indicates that the EAJ shifts southward, and vice versa. We also define the tropical WNP precipitation index (WNPPI) and the subtropical precipitation index (STPI) to facilitate the seesaw pattern in precipitation between the tropical WNP and the subtropical WNP-EA: the former is defined as the precipitation anomalies averaged over $10^{\circ}-20^{\circ} \mathrm{N}, 110^{\circ}-160^{\circ} \mathrm{E}(\mathrm{Lu}$ 2001, 2004; Wu and Wang 2001; Lu and Lu 2015; Li and Lu 2017) and the latter is defined as those averaged over $30^{\circ}-$ $40^{\circ} \mathrm{N}, 135^{\circ}-155^{\circ} \mathrm{E}$ (Lu and Lin 2009). In addition, the Niño-3 index is defined as SST anomalies averaged over $5^{\circ} \mathrm{S}-5^{\circ} \mathrm{N}$, $150^{\circ}-90^{\circ} \mathrm{W}$.

\section{Decadal change of the tropical-extratropical connections}

\section{a. The WNPSH-EAJ relationship during 1979-2017}

Figure 1 shows the $850-\mathrm{hPa}$ horizontal wind anomalies and $200-\mathrm{hPa}$ zonal wind anomalies regressed onto the normalized WNPSHI during 1979-2017. Here, the jet axis is determined as the first derivative of $200-\mathrm{hPa}$ zonal winds being zero. At $850 \mathrm{hPa}$ (Fig. 1a), the westward extension of the WNPSH corresponds to a zonally elongated anticyclonic anomaly over the subtropical WNP. In addition, there is a cyclonic anomaly over the Korean Peninsula and southern Japan and another anticyclonic anomaly over northeastern Asia. These anomalies are the manifestation of the meridional teleconnection pattern over the WNP-EA, consistent with the previous studies (e.g., Wang et al. 2001; Lu and Lin 2009). The meridional teleconnection also appears at $200 \mathrm{hPa}$ (Fig. 1b), with alternately westerly and easterly anomalies over the WNP-EA. Especially, there are westerly anomalies to the south of the EAJ axis and easterly anomalies to the north, indicating that the westerly jet shifts southward.

The meridional displacement of the EAJ also corresponds to remarkable circulation anomalies in both the lower and upper troposphere (Fig. 2), and these anomalies also manifest as the meridional teleconnection over the WNP-EA. In the lower troposphere (Fig. 2a), there is a significant anticyclonic anomaly over the subtropical WNP, albeit weaker than that associated with the WNPSHI (Fig. 1a), confirming that the southward shift of the EAJ is connected to the westward extension of the WNPSH. Compared to that associated with the WNPSHI, the cyclonic anomaly associated with the EAJI over the Korean Peninsula and Japan is stronger and more significant (Fig. 2a), which is associated with the stronger anomalies to the south and north of the jet axis in the upper troposphere (Fig. 2b). Overall, these results confirm that the meridional displacement of the EAJ is closely associated with the zonal shift of the WNPSH during 1979-2017, and this correspondence 

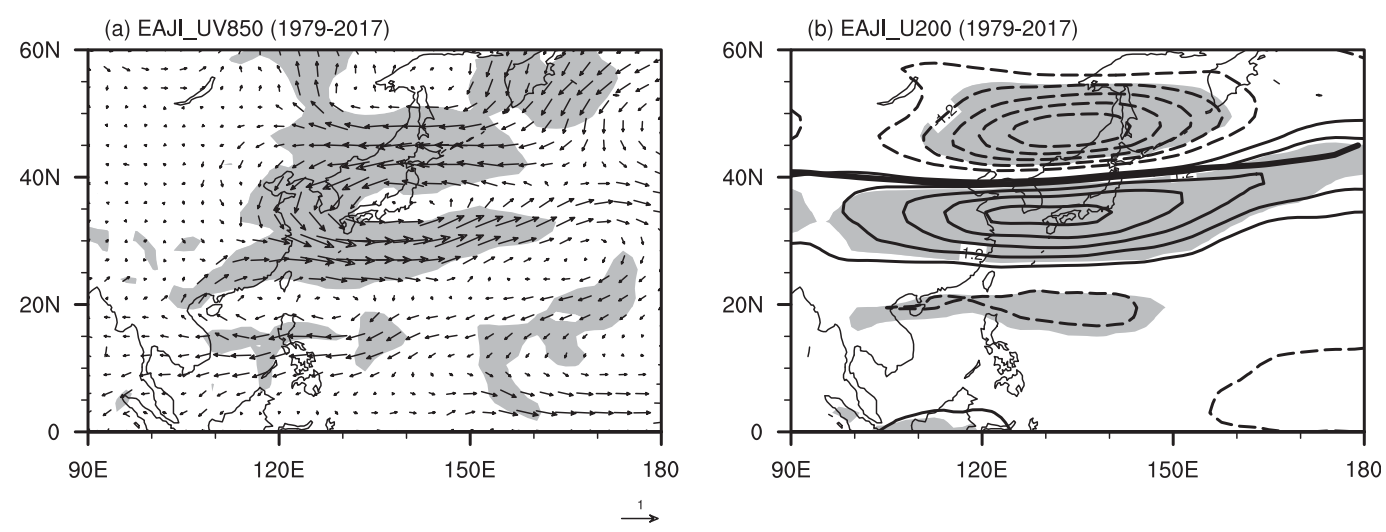

FIG. 2. As in Fig. 1, but for EAJI.

manifests as the meridional teleconnection over the WNP-EA.

Figure 3a shows the time series of the standardized WNPSHI and EAJI. Both indexes show clear interannual variations, but no distinct decadal variations. The correlation coefficient between the WNPSHI and EAJI

(a) Standarized WNPSHI and EAJI

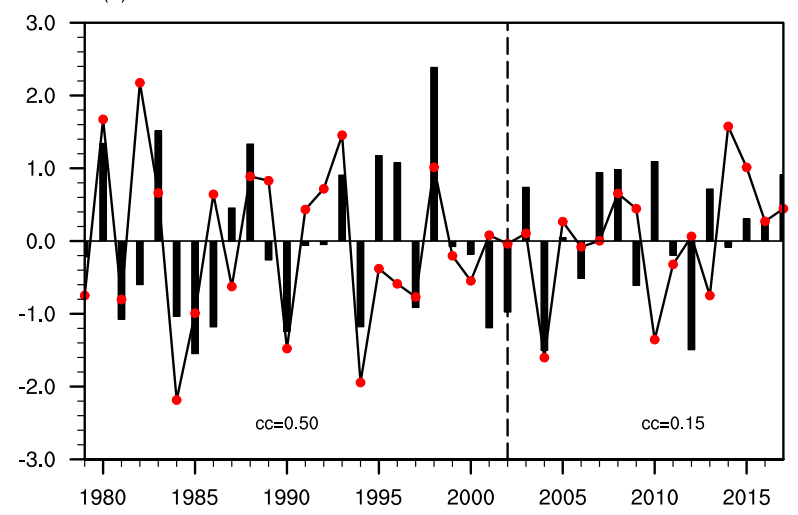

(b) 15-yr Running Corr.

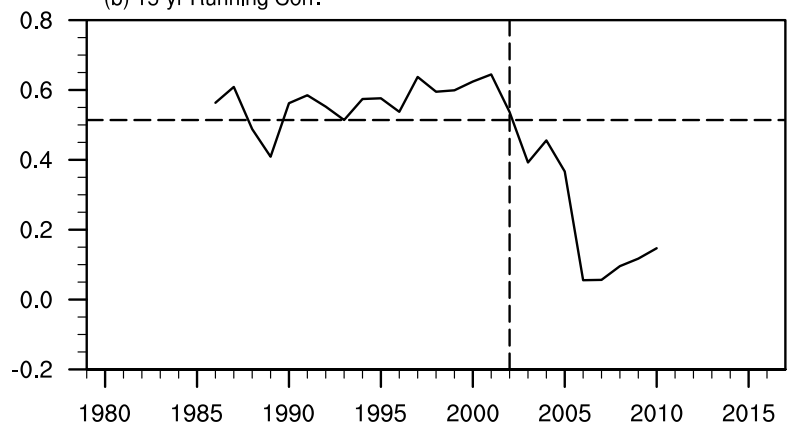

FIG. 3. (a) Time series of the standardized WNPSHI (black bar; $\mathrm{m} \mathrm{s}^{-1}$ ) and EAJI (line; $\mathrm{m} \mathrm{s}^{-1}$ ) and (b) the 15-yr running correlation coefficient between WNPSHI and EAJI. The vertical dashed lines indicate the year of 2002. The horizontal dashed line in (b) represents the significance of the correlation coefficient at $95 \%$ confidence level according to Student's $t$ test. is 0.41 during $1979-2017$, significant at the $95 \%$ confidence level. However, a 15-yr running correlation indicates that the relationship between the WNPSHI and EAJI experiences a significant decadal change at around 2002/03 (Fig. 3b). That is, the relationship is strong and significant during 1979-2002, but sharply weakened during 2003-17. The correlation coefficient between these two indexes is 0.50 in the former period, significant at $95 \%$ confidence level, but only 0.15 in the latter period. We examined the regime shift of the WNPSHIEAJI relationship based on Rodionov (2004, 2006), where the cutoff length is set to be 15 , the probability level is 0.05 , and Huber's weight parameter is 1.0 , and found that the shift occurs at 2002/03. In the following, the whole period is divided into two stages, 1979-2002 and 2003-17, to discuss the decadal change in the tropical-extratropical relationships.

\section{b. Decadal change of the WNPSH-EAJ relationship}

Figure 4 shows the 850 -hPa horizontal wind anomalies and 200-hPa zonal wind anomalies regressed onto the normalized WNPSHI during 1979-2002 and 2003-17, respectively. For the former period, the circulation anomalies for both the lower and upper troposphere resemble those during 1979-2017 (Figs. 4a,c vs Fig. 1), and are exhibited as the meridional teleconnection over the WNP-EA. The 850-hPa wind anomalies are characterized by the anticyclonic-cyclonic-anticyclonic anomalies from the tropical to extratropical WNP-EA (Fig. 4a) and the 200-hPa zonal wind anomalies feature alternately positive and negative anomalies (Fig. 4c). The westerly anomalies to the south of the jet axis and the easterly anomalies to the north are both stronger and more significant than those during 1979-2017 (Figs. 1b and 4c), confirming a stronger WNPSH-EAJ relationship.

However, during the latter period, the circulation anomalies show distinctly different features for both the 

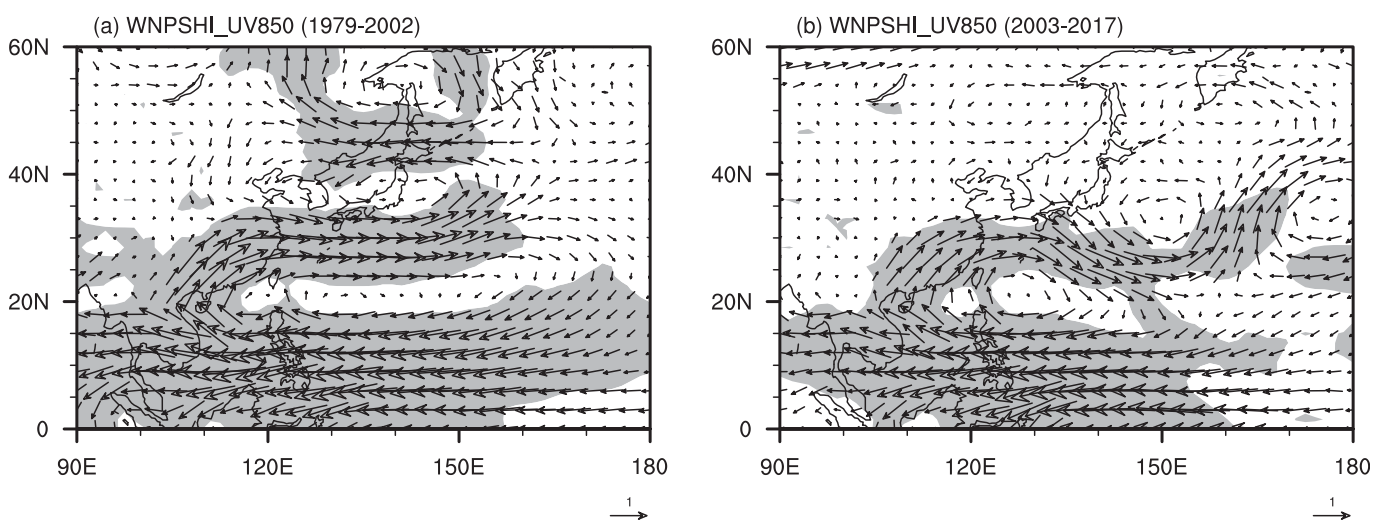

(c) WNPSHI U200 (1979-2002)
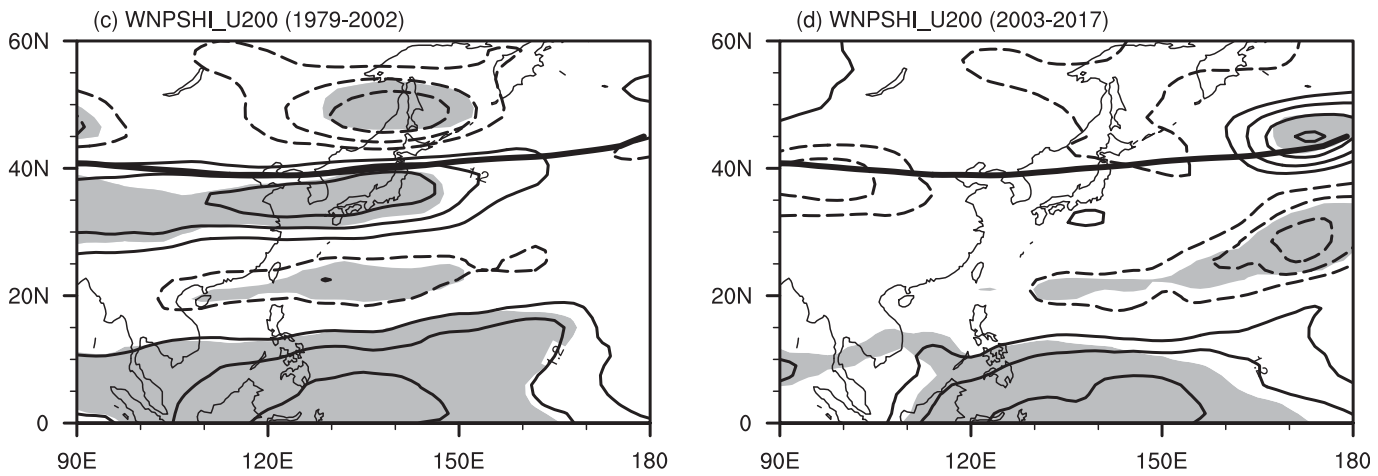

FIG. 4. Regression of (a),(b) 850-hPa horizontal winds (vectors; $\mathrm{m} \mathrm{s}^{-1}$ ) and (c),(d) 200-hPa zonal winds with respect to the normalized WNPSHI during (left) 1979-2002 and (right) 2003-17. The bold black lines in (c) and (d) represent the correspondingly climatological jet axis for 1979-2002 and 2003-17, respectively. The contour interval is $0.5 \mathrm{~m} \mathrm{~s}^{-1}$, and zero contours are omitted. Shading in (a) and (b) indicates that either zonal or meridional wind anomalies are significant at the $95 \%$ confidence level based on Student's $t$ test, and shading in (c) and (d) refers to the significant zonal wind anomalies.

lower and upper troposphere. In the lower troposphere (Fig. 4b), there is only a significant anticyclonic anomaly over the subtropical WNP, but the midlatitude cyclonic anomaly is absent. Without the midlatitude cyclonic anomaly, the north flank of the anticyclonic anomaly shifts from westerly to northwesterly anomalies, which would result in the absence of the subtropical WNP-EA precipitation anomalies, as discussed in latter analyses. In addition, a cyclonic anomaly appears over southeast Japan and an anticyclonic anomaly east of this cyclonic anomaly, but with marginal significance. On the other hand, in the upper troposphere (Fig. 4d), significant anomalies only appear over the tropical WNP-EA, but not to the south and north of the EAJ axis, consistent with the weak relationship between the WNPSH and EAJ. In addition, there are significant negative and positive anomalies over the extratropical WNP. These results confirm that the WNPSH-EAJ relationship becomes obscure and the meridional teleconnection pattern cannot be established during the latter period.
Figure 5 shows the 850 -hPa horizontal wind anomalies and 200-hPa zonal wind anomalies regressed onto the normalized EAJI during 1979-2002 and 2003-17, respectively. For both periods, the 200 -hPa zonal wind anomalies show significant westerly anomalies to the south of the jet axis and easterly anomalies to the north (Figs. 5c,d). However, the circulation anomalies in the lower troposphere are distinctly different between these two periods. In the former period (Fig. 5a), the wind anomalies resemble those for 19792017 (Fig. 2a) and there is a significant anticyclonic anomaly over the subtropical WNP, corresponding to the westward extension of the WNPSH. While in the latter period (Fig. 5b), the anticyclonic anomaly disappears and the wind anomalies are only characterized by a significant cyclonic anomaly over the midlatitudes. Using the NCEP2 reanalysis dataset, Huang et al. (2018) reported similar changes in circulation anomalies associated with the leading mode of the 200-hPa zonal winds over East Asia, which exhibits as the meridional displacement of the EAJ, in 

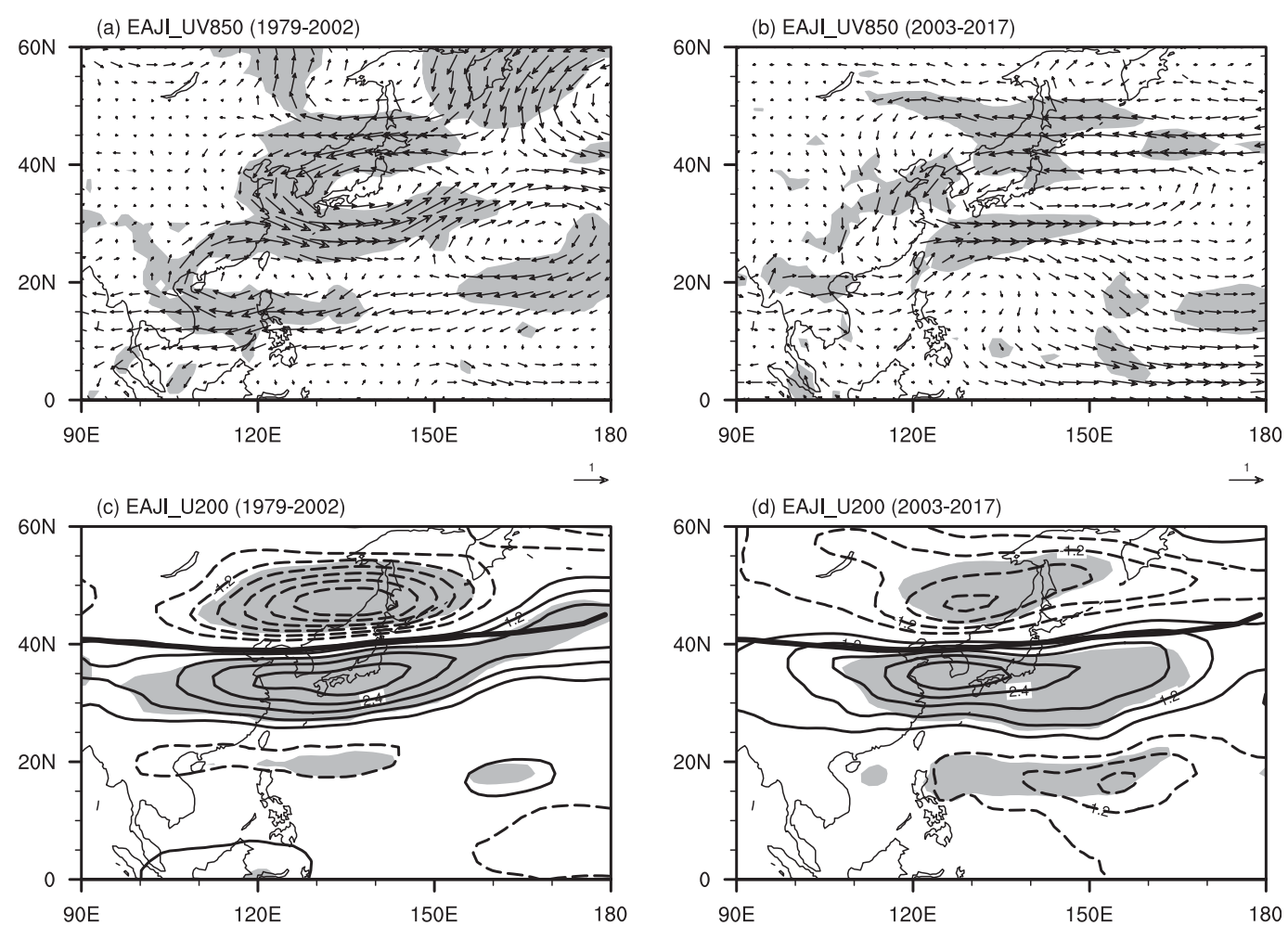

FIG. 5. As in Fig. 4, but for EAJI.

the late 1990s. Therefore, the present results are not sensitive to the choice of EAJ index.

\section{c. Decadal change of the seesaw pattern between tropical and subtropical WNP-EA precipitation}

The previous subsection indicates that the meridional teleconnection, illustrated by the WNPSH-EAJ relationship, is absent during 2003-17. Associated with the breakdown of the circulation teleconnection, precipitation anomalies over the WNP-EA also experience a significant decadal change (Fig. 6). During the former period, precipitation anomalies associated with the WNPSHI and EAJI both exhibit as significant triple pattern over the WNP-EA (Figs. 6a,c). There are negative anomalies over the tropical WNP, positive anomalies along the East Asian rainband, and negative ones over northeastern Asia. However, during the latter period, these well-organized anomalies are disrupted. For the WNPSHI-related anomalies (Fig. 6b), the most striking feature is the weak rainfall anomalies over the subtropical region. The rainfall anomalies associated with the WNPSHI averaged over $30^{\circ}-40^{\circ} \mathrm{N}, 135^{\circ}-155^{\circ} \mathrm{E}$, which is used to represent the subtropical WNP-EA precipitation in a previous study ( $\mathrm{Lu}$ and Lin 2009), is $0.66 \mathrm{~mm} \mathrm{day}^{-1}$ during the former period but only $0.07 \mathrm{~mm} \mathrm{day}^{-1}$ during the latter period. Instead, positive anomalies appear over the midlatitude WNP, corresponding to the anomalous lower-tropospheric cyclone there (Fig. 4b).

For the EAJI-related anomalies (Fig. 6d), on the other hand, enhanced rainfall also appears along the East Asian rainband, becoming weaker and less significant than the former period. The most impressive feature for this case is that the rainfall anomalies over the tropical WNP are sharply reduced: the anomalies averaged over $10^{\circ}-20^{\circ} \mathrm{N}, 110^{\circ}-160^{\circ} \mathrm{E}$ are -0.67 and $-0.14 \mathrm{~mm} \mathrm{day}^{-1}$ for the former and latter periods, respectively. Besides, the correlation coefficient between the WNPPI and STPI is -0.57 in the former period but only -0.08 in the latter period. These results are partially consistent with previous studies (Huang et al. 2018; Xu et al. 2019). Huang et al. (2018) reported that after the late 1990s, both the WNPSH-East Asian rainfall relationship and the EAJ-tropical WNP convection relationship are weakened. Xu et al. (2019) also showed that the extratropical anomalies associated with the meridional teleconnection have been weakened after the late 1990s.

Table 1 lists the correlation coefficients between the indexes that feature the meridional teleconnection during the former and latter periods. It is found that the relationship between the WNPPI and the WNPSHI survives during the latter period; that is, suppressed 

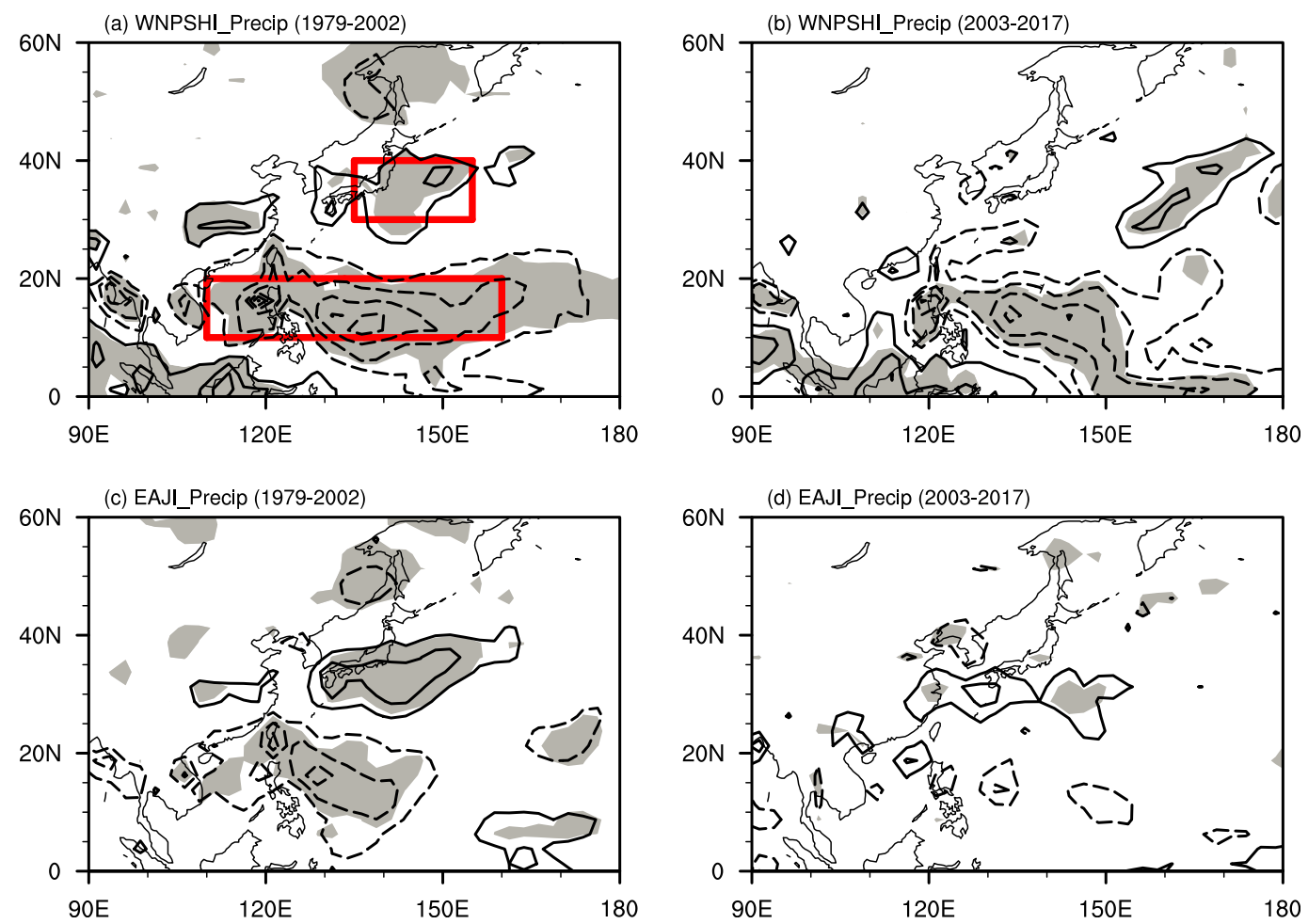

FIG. 6. Regression of precipitation with respect to the normalized (a),(b) WNPSHI and (c),(d) EAJI during (left) 1979-2002 and (right) 2003-17. The marked regions in (a) represent the areas used to define the WNPPI and STPI, respectively. The contour interval is $0.5 \mathrm{~mm} \mathrm{day}^{-1}$, and zero contours are omitted. The shading denotes the $95 \%$ confidence level based on Student's $t$ test.

convection over the tropical WNP can induce the anticyclonic anomaly. However, the WNPSHI/WNPPISTPI relationship becomes obscure, suggesting that the anticyclonic anomaly cannot induce the subtropical precipitation anomalies, and thus breaks down the seesaw pattern in precipitation between the tropical and subtropical WNP-EA. This phenomenon is further explored.

It has been well known that the subtropical East Asian rainband features a strong meridional gradient of moisture in the lower troposphere (Chen and Chang 1980; Ding 1992). Therefore, the equivalent potential temperature $\theta_{e}$, which combines both moisture and temperature, is widely used to describe the subtropical rainfall (Zhu et al. 2000; Park et al. 2015; Li and Lu 2017, 2018; Gao et al.

TABLE 1. The correlation coefficients between the indexes that feature the meridional teleconnection during 1979-2002 and 200317 , respectively. Boldface numbers are significant at the $95 \%$ confidence level based on Student's $t$ test.

\begin{tabular}{lccc}
\hline & EAJI & WNPPI & STPI \\
\hline WNPSHI & $\mathbf{0 . 5 0} / 0.15$ & $\mathbf{- 0 . 9 2} /-\mathbf{0 . 9 2}$ & $\mathbf{0 . 5 9} / 0.04$ \\
EAJI & & $-\mathbf{0 . 5 2} /-0.18$ & $\mathbf{0 . 7 9} / 0.40$ \\
WNPPI & & & $-\mathbf{0 . 5 7} /-0.08$ \\
\hline
\end{tabular}

2019). A higher value of $\theta_{e}$ indicates more humid and warmer conditions. In climatological mean, $\theta_{e}$ decreases with latitude over East Asia and shows its largest gradient along the rainband, favoring enhanced precipitation by inducing the generation of convective instability (Ninomiya 1984; Ninomiya and Shibagaki 2007).

Figure 7 shows the $\theta_{e}$ anomalies at $850 \mathrm{hPa}$ regressed onto the normalized WNPSHI during 1979-2002 and 2003-17, respectively. The significant precipitation anomalies and $850-\mathrm{hPa}$ wind anomalies are also shown to facilitate comparison. The corresponding meridional gradient anomalies of $\theta_{e}$ averaged over $135^{\circ}-155^{\circ} \mathrm{E}$ are shown in the right-hand panels. Here, a positive value indicates the decrease of $\theta_{e}$ in the northward direction and thus the enhancement of the $\theta_{e}$ gradient. During the former period (Fig. 7a), there are positive $\theta_{e}$ anomalies to the south of $35^{\circ} \mathrm{N}$ and negative $\theta_{e}$ anomalies to the north of this latitude, which enhance the meridional gradient of climatological $\theta_{e}$ over the subtropical WNP-EA. The difference in $\theta_{e}$ anomalies between the southern edge (averaged along $30^{\circ} \mathrm{N}, 135^{\circ}-155^{\circ} \mathrm{E}$ ) and the northern edge (averaged along $40^{\circ} \mathrm{N}, 135^{\circ}-155^{\circ} \mathrm{E}$ ) of the subtropical WNP-EA is $0.89 \mathrm{~K}$, and this increase is about $7.5 \%$ of the climatological difference between the southern and 
(a) WNPSHI_ $\theta e \_850 \mathrm{hPa}(1979-2002)$

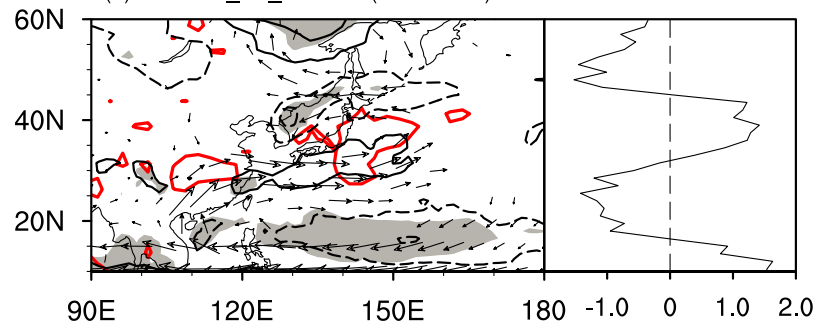

(b) WNPSHI_ $\theta e \_850 \mathrm{hPa}(2003-2017)$

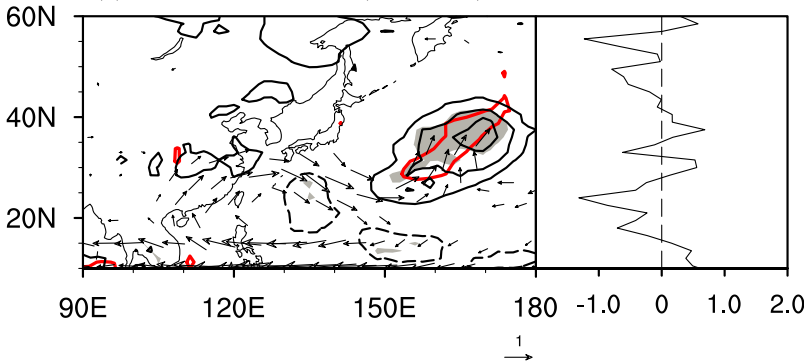

FIG. 7. Regression of 850-hPa equivalent potential temperature $\theta_{e}$ anomalies with respect to the normalized WNPSHI during (a) 19792002 and (b) 2003-17. The contour interval is $0.2 \mathrm{~K}$, and zero contours are omitted. Shading denotes the $95 \%$ confidence level based on Student's $t$ test. The scopes (red lines) of the significant positive precipitation anomalies and the significant horizontal wind anomalies (vectors) at $850 \mathrm{hPa}$ are also given for comparison. Precipitation anomalies are based on the GPCP grid data. The curves in the right-hand panels show the corresponding meridional gradient anomalies $\left(10^{-6} \mathrm{~K} \mathrm{~km}^{-1}\right)$ of $\theta_{e}$, which are averaged over $135^{\circ}-155^{\circ} \mathrm{E}$.

northern edges during this period $(11.80 \mathrm{~K})$. The enhanced $\theta_{e}$ gradient anomalies correspond well to the enhanced precipitation anomalies. This is expected, as the enhanced meridional gradient of $\theta_{e}$ favors the generation of convective instability, and thus results in large amounts of precipitation (Ninomiya and Shibagaki 2007). In addition, the positive and negative $\theta_{e}$ anomalies correspond well to the westerly and easterly anomalies, respectively, suggesting that the WNPSHI-related circulation anomalies play an important role in the formation of $\theta_{e}$ anomalies. During the latter period (Fig. 7b), however, the distribution of $\theta_{e}$ anomalies becomes quite different. There are no clear $\theta_{e}$ and its meridional gradient anomalies over the subtropical WNP-EA and thus no significant rainfall anomalies (Fig. $7 \mathrm{~b}$ ). The reason for the absence of the $\theta_{e}$ anomalies in the latter period will be discussed in the following.

(a) Clim $\theta e \quad 850 \mathrm{hPa}(1979-2002)$

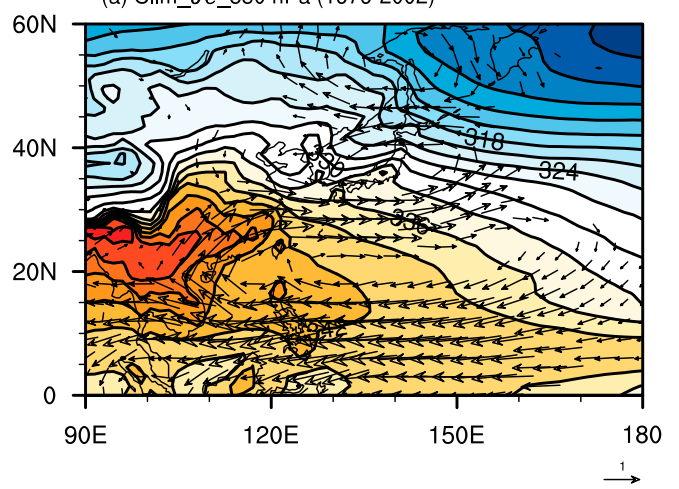

Figure 8 shows the climatological mean of $\theta_{e}$ and the significant horizontal wind anomalies associated with the normalized WNPSHI at $850 \mathrm{hPa}$ during the former and latter periods, respectively. At both periods, high $\theta_{e}$ values, which represent the warm and moist air, appear over South China and Indochina. The $\theta_{e}$ values decrease with both latitude and longitude, particularly with latitude over central China, which is a typical feature of mei-yu. Although the patterns of mean $\theta_{e}$ are similar between the former and latter periods, the match between the wind anomalies and mean $\theta_{e}$ is quite different. In the former period (Fig. 8a), the westerly anomalies associated with the WNP anticyclonic anomaly travel from high to low $\theta_{e}$ regions over the subtropical WNP, suggesting that there is positive horizontal advection of $\theta_{e}$. In addition, the easterly and northeasterly anomalies associated with the midlatitude cyclonic anomaly travel
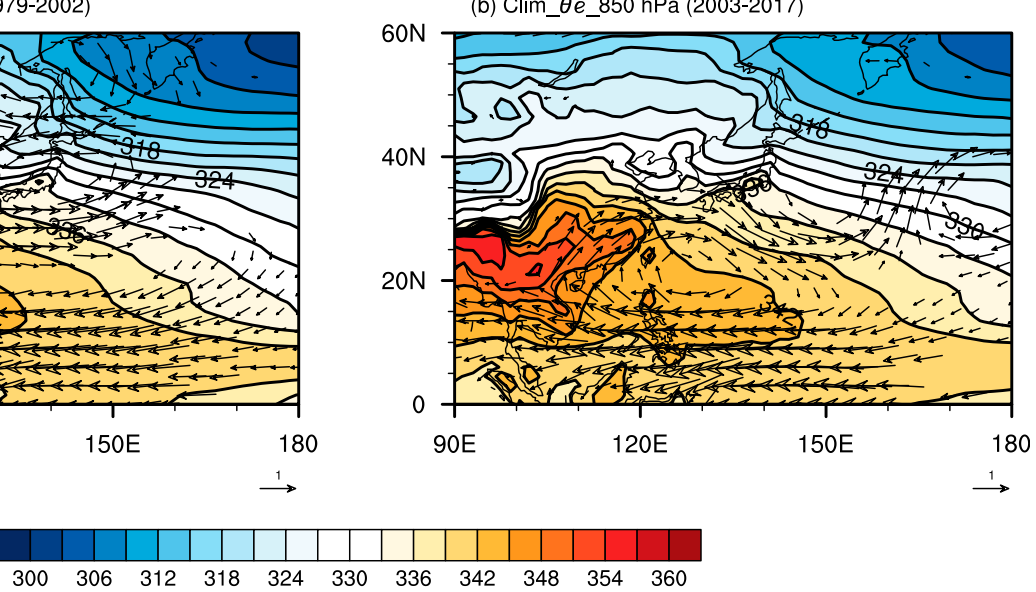

FIG. 8. Climatological mean of equivalent potential temperature $\theta_{e}$ (shading and contours) and the 850-hPa horizontal winds (vectors; $\mathrm{m} \mathrm{s}^{-1}$ ) with respect to the normalized WNPSHI during (a) 1979-2002 and (b) 2003-17. The contour interval is $3.0 \mathrm{~K}$, and only vectors significant at $95 \%$ confidence level based on Student's $t$ test are shown. 
from low to high $\theta_{e}$ regions over East Asia, suggesting that there is negative horizontal advection of $\theta_{e}$. As a result, positive and negative $\theta_{e}$ anomalies appear over the south and north of the subtropical WNP-EA, respectively, and the $\theta_{e}$ meridional gradient is enhanced (Fig. 7a).

In contrast, in the latter period (Fig. 8b), the north flank of the anticyclonic anomaly shifts from westerly to northwesterly anomalies, in association with the absence of the midlatitude cyclonic anomaly. These wind anomalies are nearly parallel to the climatological $\theta_{e}$ contours, and thus there is no horizontal advection of $\theta_{e}$ over the subtropical WNP-EA. As a result, the WNPSHI-related circulation anomalies cannot induce $\theta_{e}$ meridional gradient anomalies and the associated precipitation there (Fig. 7b). In addition, there are also no clear $\theta_{e}$ anomalies in the north of the subtropical WNP-EA, as a result of the absence of the midlatitude cyclonic anomaly (Figs. $7 \mathrm{~b}$ and $8 \mathrm{~b}$ ).

Previous studies documented that the subtropical WNP-EA precipitation anomalies, as the latent heat source, can in turn induce a zonally elongated cyclonic anomaly in the midlatitude WNP-EA, which appears in both the lower and upper troposphere, and thus enhance the meridional teleconnection ( $\mathrm{Lu}$ and Lin 2009). The present results indicate that the subtropical WNP anticyclonic anomaly cannot induce the subtropical rainfall anomalies in the latter period. This is because the north flank of the anticyclonic anomaly shifts from westerly to northwesterly anomalies and there is no transportation of equivalent potential temperatures. Therefore, the feedback role of the subtropical precipitation anomalies in enhancing the meridional teleconnection becomes obscure, further favoring the breakdown of the teleconnection.

Overall, the present results demonstrated that the meridional teleconnection, which can be illustrated by the WNPSH-EAJ relationship or the seesaw pattern in precipitation between the tropical WNP and subtropical WNP-EA, is well established during 1979-2002. However, the tropical-extratropical connections are sharply weakened during 2003-17. The reason for the breakdown of the meridional teleconnection is to be discussed in the next section.

\section{Possible mechanism}

In the previous section, it was shown that the WNPSH-EAJ relationship is well established during 1979-2002, but becomes absent during 2003-17. In this section, we would further explore the possible mechanism responsible for this change.

It is notable that the decadal change in the WNPSHIEAJI relationship could just be a result of the weakened interannual variability of the WNPSHI or the EAJI. In fact, the standard deviations of both indexes indeed decrease since 2003: the standard deviation of the WNPSHI (EAJI) is $2.63 \mathrm{~m} \mathrm{~s}^{-1}\left(4.84 \mathrm{~m} \mathrm{~s}^{-1}\right)$ during 19792002 , but reduced to $2.04 \mathrm{~m} \mathrm{~s}^{-1}\left(3.60 \mathrm{~m} \mathrm{~s}^{-1}\right)$ during $2003-$ 17. To test the effect of the change in the variability of the WNPSHI, we exclude the four years that contribute most to the standard deviation of the WNPSHI in the former period (1980, 1983, 1985, and 1998) and make the standard deviation comparable to that in the latter period (2.07 vs $\left.2.04 \mathrm{~m} \mathrm{~s}^{-1}\right)$. The correlation coefficient between the WNPSHI and the EAJI in the former period becomes 0.34 , still larger than that in the latter period (0.15). These results indicate that the decrease of the interannual variability of WNPSHI is not the only reason that induces the change in the WNPSHI-EAJI relationship. Similarly, we exclude the years which contribute most to the standard deviation of the EAJI in the former period (1982, 1984, 1990, and 1994), and make its standard deviation comparable to that in the latter period ( $3.55 \mathrm{vs} 3.60 \mathrm{~m} \mathrm{~s}^{-1}$ ). The correlation coefficient between these two indexes in the former period becomes 0.56 , even larger than that before excluding these years (0.50). These results indicate that the decadal change in the WNPSHI-EAJI relationship should not be attributed to the change in the interannual variability of the EAJI, and the other possible mechanisms should be explored.

Therefore, we hypothesize that large-scale environmental conditions, in particular SSTs in the tropics, may experience a certain change, and induce the decadal change in the WNPSH-EAJ relationship. Figure 9 shows the evolution of SST anomalies from the preceding winter [December-February (DJF)] to summer associated with the normalized WNPSHI and EAJI during 1979-2002. The SST anomalies associated with the WNPSHI exhibit as the decay of canonical El Niño (left panels of Fig. 9). There are significant positive SST anomalies over the tropical eastern Pacific and negative ones over the western Pacific in preceding winter (Fig. 9a), which induce an anticyclonic anomaly over the subtropical WNP (Wang et al. 2000). It is well known that this anticyclonic anomaly is maintained from winter to the following summer, through a positive feedback role of atmosphere-ocean interaction in the WNP (Wang et al. 2000) or the Indian Ocean capacitor effect (Terao and Kubota 2005; Yang et al. 2007; Li et al. 2008; Xie et al. 2009, 2016). Indeed, the positive SST anomalies over the tropical eastern Pacific gradually decay and become weak and insignificant in the following summer (Fig. 9e). Instead, SST anomalies over the tropical Indian Ocean and South China Sea become strong and significant, consistent with these previous theories. 
1979-2002
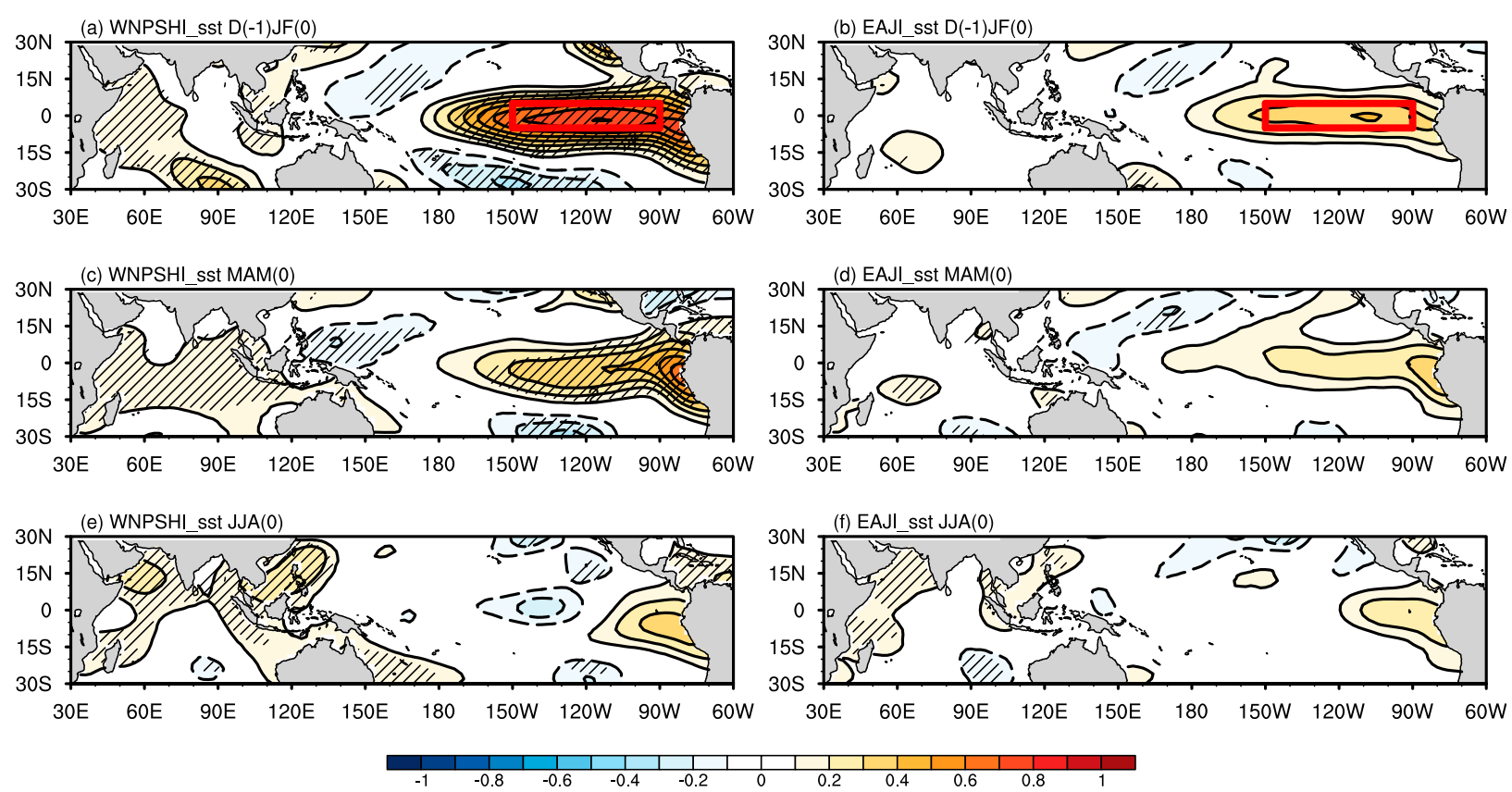

FIG. 9. Evolution of sea surface temperature (SST) anomalies $\left({ }^{\circ} \mathrm{C}\right)$ from the preceding winter $[\mathrm{D}(-1) \mathrm{JF}(0)]$ to the subsequent summer [JJA(0)] with respect to the normalized (left) WNPSHI and (right) EAJI during 1979-2002. Zero contours are omitted. Hatching indicates that the SST anomalies are significant at the 95\% confidence level based on Student's $t$ test. The marked region is used to define the winter Niño-3 index (see text for definitions), which is used for latter analysis.

The evolution of SST anomalies associated with the EAJI resembles that with the WNPSHI (right panels of Fig. 9). It is characterized by canonical El Niño decay from the preceding winter to summer over the tropical eastern Pacific, and positive SST anomalies appear over the tropical Indian Ocean in simultaneous summer (Fig. 9f), although these anomalies are weaker and less significant than those associated with the WNPSHI. The link between ENSO and the meridional displacement of the EAJ has also been extensively studied (e.g., Shaman and Tziperman 2007; Lin and $\mathrm{Lu}$ 2009; Qu and Huang 2011; Hong and Lu 2016). The decay of canonical El Niño and the associated positive SST anomalies in tropical Indian Ocean in simultaneous summer induce tropospheric warming in the tropics, and the associated thermal wind result in the southward shift of the midlatitude jet (Held and Hou 1980; Bretherton and Sobel 2003; Seager et al. 2003; Chen et al. 2008; Lu et al. 2008; Gong et al. 2010; Sun et al. 2013). Overall, these results indicate that the correspondence between the zonal shift of the WNPSH and the meridional displacement of the EAJ is modulated by canonical ENSO in the former period.

Figure 10 shows the evolution of SST anomalies from the preceding winter to summer associated with the normalized WNPSHI and EAJI during 2003-17. The evolution of SST anomalies is quite different from that in the former period, for both WNPSHI and EAJI. The anomalies associated with the westward extension of the WNPSH look like the decay of central Pacific (CP) El Niño (left panels of Fig. 10; Ashok et al. 2007; Kao and $\mathrm{Yu}$ 2009), although with marginal significance. The correlation coefficient between the CP El Niño index defined by Ashok et al. (2007) and WNPSHI in the latter period is 0.33 , larger than that between the preceding winter Niño-3 index and the WNPSHI (0.20). There are positive SST anomalies over the tropical central Pacific during previous winter (Fig. 10a). These positive anomalies decay rapidly and negative SST anomalies appear over the tropical central and eastern Pacific during summer (Figs. 10c,e). It has been reported that cooler (warmer) SST in the tropical central and eastern Pacific can favor less (more) rainfall over the tropical WNP and thus an anticyclonic (cyclonic) anomaly to the northwest (Lau and Nath 2006; Wang et al. 2013). These results are also consistent with some recent studies ( $\mathrm{He}$ and $\mathrm{Wu}$ 2018; Wu and Wang 2019), who reported that the tropical WNP precipitation or anticyclonic anomaly is more associated with the simultaneous SST anomalies in the tropical central and eastern Pacific in the recent decade.

By contrast, the SST anomalies associated with the EAJI are basically opposite signed with those associated 

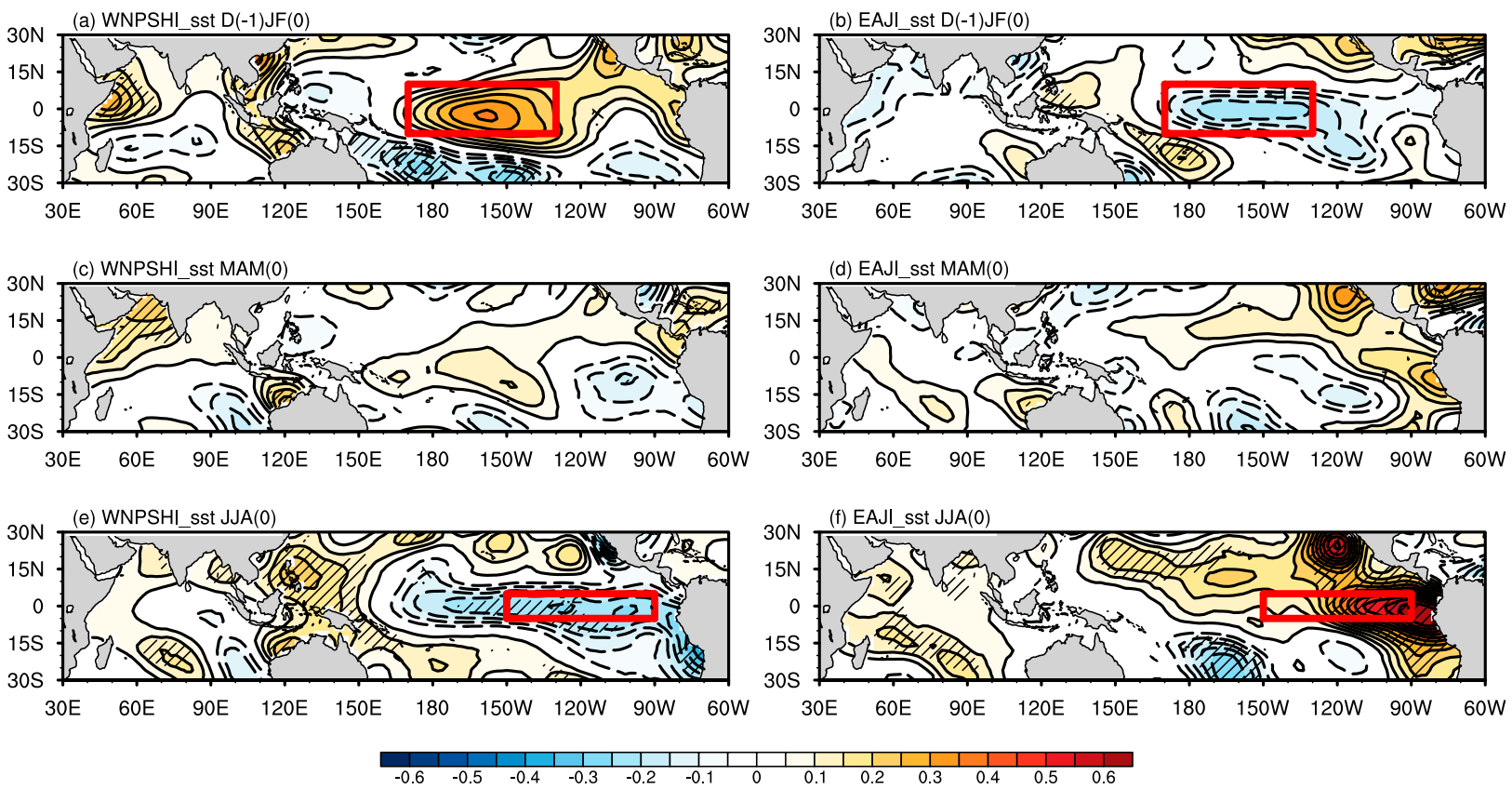

FIG. 10. As in Fig. 9, but for 2003-17. Marked regions are used to define the CP_SST index and summer Niño-3 index (see text for definitions), which are used for latter analyses.

with the WNPSHI over the tropical central eastern Pacific, resembling the CP La Niña decay (right panels of Fig. 10). Negative SST anomalies appear over the tropical central Pacific in the preceding winter (Fig. 10b). These negative anomalies become much weaker in the following spring (Fig. 10d). In summer, the SST anomalies are characterized by significant positive anomalies over the tropical central and eastern Pacific (Fig. 10f). These positive SST anomalies can induce warming in the tropical troposphere and the southward shift of the midlatitude westerly jet, as mentioned previously.

The present results indicate that during the former period, the WNPSH and the EAJ are both associated with the decay of canonical El Niño and the subsequently positive SST anomalies over the tropical Indian Ocean in summer. However, during the latter period, the decay of CP-like El Niño and the associated negative SST anomalies over the tropical central and eastern Pacific in summer favor a nearly conversed WNP-EAJ correspondence (i.e., an anticyclonic anomaly over the subtropical WNP but a northward displaced EAJ). The transfer of dominant role from canonical El Niño in the former period to CP-like El Niño in the latter period is consistent with previous studies, which have reported that CP El Niño has occurred more frequently and exhibits as the leading mode of Pacific SST anomalies in the recent two decades (e.g., Yeh et al. 2009; McPhaden
2012; Hu et al. 2013; Xiang et al. 2013; Wen et al. 2014; Yu et al. 2015).

Figure 11 shows the $850-\mathrm{hPa}$ horizontal wind anomalies and 200-hPa zonal wind anomalies regressed onto the normalized previous winter Niño-3 index during 1979-2002 and 2003-17, respectively. During the former period (Figs. 11a,c), the circulation anomalies in the lower and upper troposphere are both characterized by the meridional teleconnection. Especially, in the lower troposphere (Fig. 11a), there is an anticyclonic anomaly over the subtropical WNP, corresponding to the westward extension of the WNPSH; and in the upper troposphere (Fig. 11c), there are significant positive zonal wind anomalies to the south of the westerly jet and negative anomalies to the north, corresponding to the southward displacement of the EAJ.

However, during the latter period, circulation anomalies in the lower and upper troposphere both become weak and insignificant, and the meridional teleconnection is absent (Figs. 11b,d). The correlation coefficient between the previous winter Niño-3 index and the WNPSHI is 0.68 during 1979-2002, significant at $99 \%$ confidence level, but it sharply reduces to 0.18 during 2003-17; and that with the EAJI is 0.33 during the former period, but -0.16 during the latter period (Table 2). These results indicate that the zonal shift of the WNPSH and the meridional displacement of the EAJ are less affected by canonical El Niño in the latter period. 

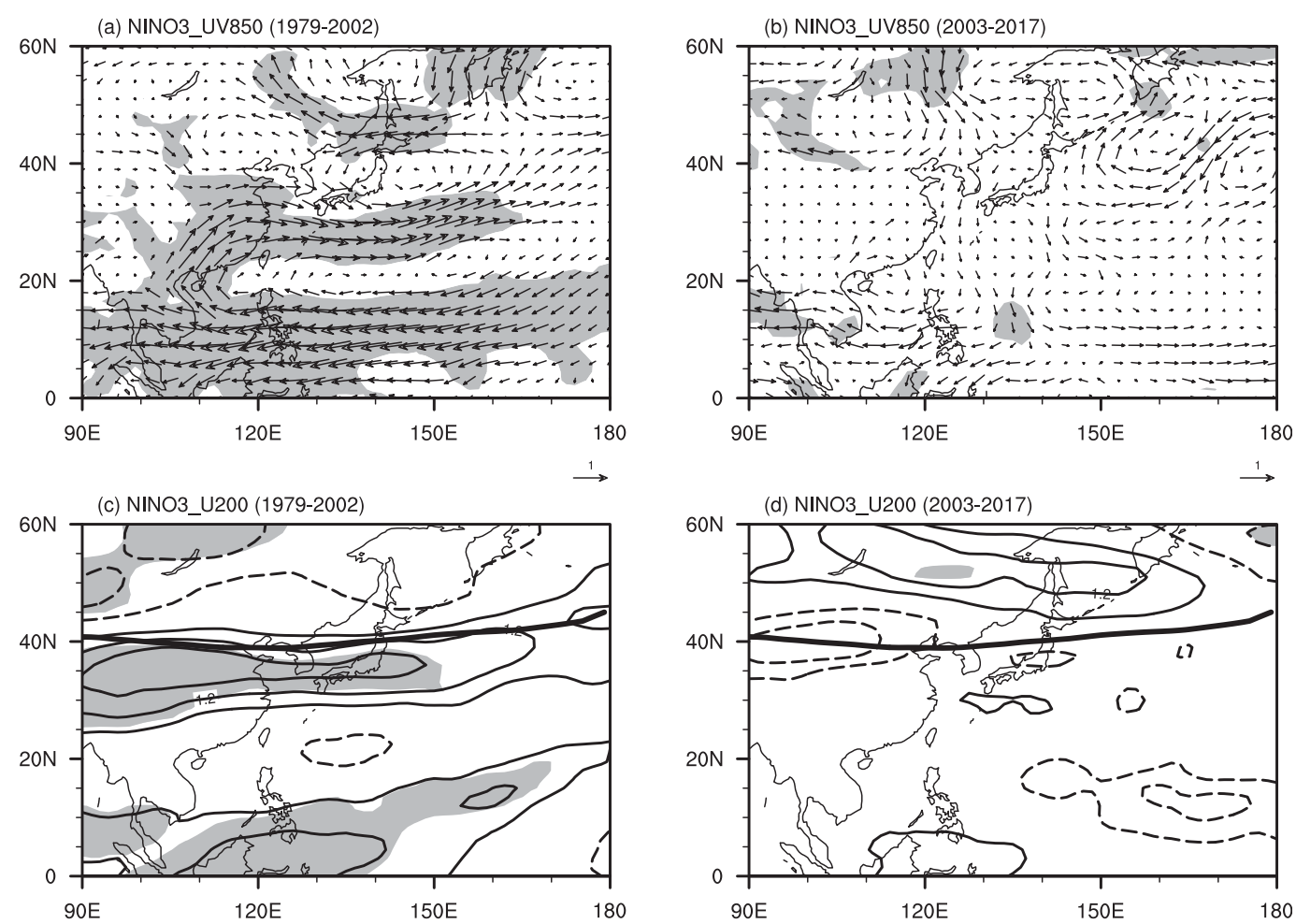

FIG. 11. Regression of (a),(b) 850-hPa horizontal winds (vectors; $\mathrm{m} \mathrm{s}^{-1}$ ) and (c),(d) 200-hPa zonal winds with respect to the normalized previous winter Niño-3 index during (left) 1979-2002 and (right) 2003-17. The bold black lines in (c) and (d) represent the correspondingly climatological jet axis for 1979-2002 and 2003-17, respectively. The contour interval is $0.5 \mathrm{~m} \mathrm{~s}^{-1}$, and zero contours are omitted. Shadings in (a) and (b) indicate that either zonal or meridional wind anomalies are significant at the 95\% confidence level based on Student's $t$ test and in (c) and (d) refer to the significant zonal wind anomalies.

To illustrate the reason for the weakened impact of canonical El Niño on the meridional teleconnection in the latter period, Fig. 12 shows the evolution of SST anomalies from the preceding winter to summer associated with the normalized previous winter Niño-3 index during 1979-2002 and 2003-17, respectively. During the former period, the evolution of SST anomalies resembles that associated with the WNPSHI (left panels of Fig. 9 vs left panels of Fig. 12), exhibiting as the decay of canonical El Niño in tropical eastern Pacific. Significant positive anomalies appear over the tropical Indian Ocean in summer (Fig. 12e), maintaining the subtropical anticyclonic anomaly by the Indian Ocean capacitor effect. During the latter period, SST evolution also exhibits as the decay of El Niño, but shows some appreciable differences. First, the positive centers of the SST anomalies over the tropical Pacific locate more westward in previous winter and spring - that is, around $150^{\circ} \mathrm{W}$ in the latter period (Figs. 12b,d) but $125^{\circ} \mathrm{W}$ in the former period (Figs. 12a,c). Therefore, the evolution of SST anomalies during the latter period looks more like the decay of CP El Niño, consistent with the enhanced frequency of CP El Niño in the latter period (McPhaden 2012; Hu et al. 2013; Xiang et al. 2013; Yu et al. 2015). Second, for the latter period, positive anomalies over the Indian Ocean are very weak during summer, suggesting that the bridge role of the Indian Ocean is weakened (Fig. 12f). Therefore, the WNPSH is less affected by SST anomalies in the tropical eastern Pacific during previous winter in the latter period. On the other hand, as the positive SST anomalies over the tropical Indian Ocean and central eastern Pacific in simultaneous summer are much weaker during the latter period (Figs. 12e,f), the ENSO-related warming in the

TABLE 2. The correlation coefficients between the Niño-3 index, for the previous winter and simultaneous summer, and the WNPSHI and EAJI during 1979-2002 and 2003-17, respectively. Boldface numbers are significant at the $95 \%$ confidence level based on Student's $t$ test.

\begin{tabular}{lcc}
\hline & $\begin{array}{c}\text { Previous winter } \\
\text { Niño-3 index }\end{array}$ & $\begin{array}{c}\text { Simultaneous } \\
\text { summer Niño-3 index }\end{array}$ \\
\hline WNPSHI & $\mathbf{0 . 6 8} / 0.18$ & $-0.02 /-0.40$ \\
EAJI & $0.33 /-0.16$ & $0.14 / \mathbf{0 . 5 7}$ \\
\hline
\end{tabular}


1979-2002
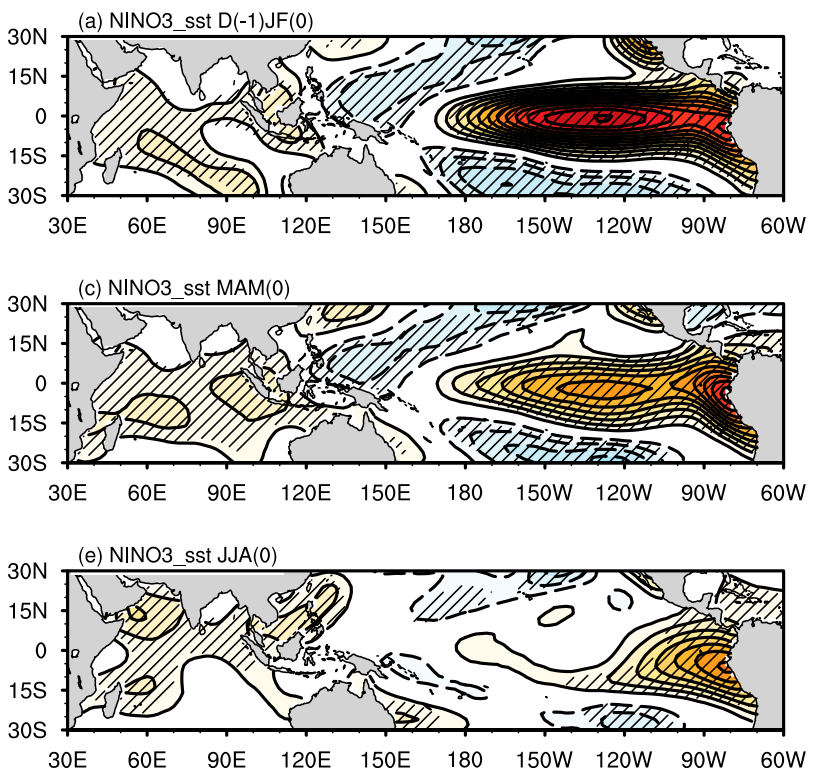
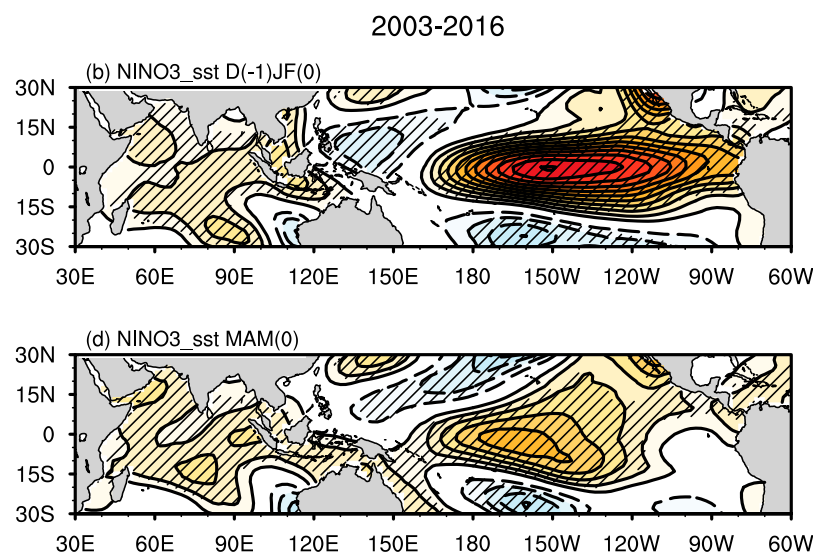
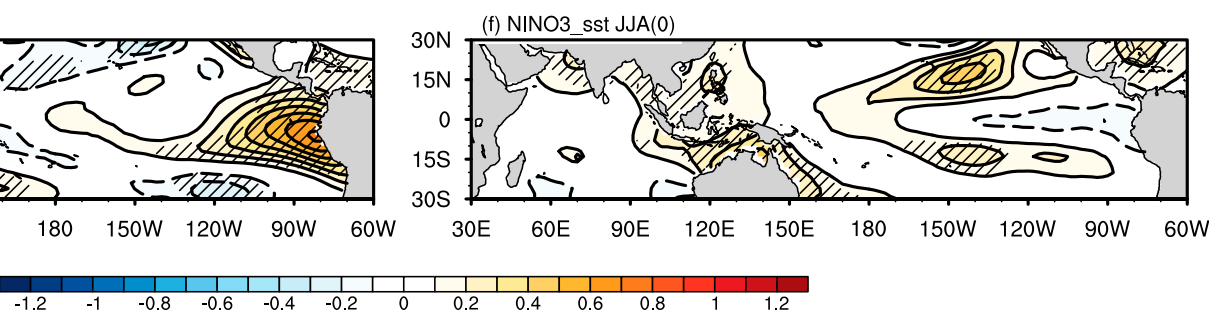

FIG. 12. Evolution of sea surface temperature (SST) anomalies $\left({ }^{\circ} \mathrm{C}\right)$ from the preceding winter $[\mathrm{D}(-1) \mathrm{JF}(0)]$ to the subsequent summer [JJA(0)] with respect to the normalized previous winter Niño-3 index during (left) 1979-2002 and (right) 2003-17. Zero contours are omitted. Hatching indicates that the SST anomalies are significant at the 95\% confidence level based on Student's $t$ test.

tropical troposphere is also weakened (not shown). As a result, the impact of ENSO on the meridional displacement of the EAJ is also weakened.

The present results indicate a breakdown of the relationship between the meridional teleconnection and canonical ENSO in the latter period. In this period, the SST anomalies over the tropical central and eastern Pacific in simultaneous summer seem to become important. It has been reported that warm SST anomalies over the tropical central and eastern Pacific in simultaneous summer are favorable for the eastward retreat of the WNPSH (Wang et al. 2013) and the southward shift of the EAJ ( $\mathrm{Lu} 2005$; Lin 2010). The correlation coefficient between the summer Niño-3 index and the EAJI during $2003-17$ is 0.57 , significant at $95 \%$ confidence level; and that between the summer Niño-3 index and the WNPSHI is -0.40 (Table 2). These results confirm that the SST anomalies over the tropical central and eastern Pacific in simultaneous summer tend to result in a nearly inversed WNPSH-EAJ correspondence during the latter period.

On the other hand, the SST anomalies over the tropical central Pacific in previous winter is opposite signed with those over the tropical central eastern Pacific in the following summer during the latter period (Fig. 10). This is similar to the CP-like El Niño (La Niña) decay and to some extent consistent with previous studies (Feng et al.
2011; Li et al. 2015), which reported that the SST anomalies associated with the $\mathrm{CP}$ El Niño decay rapidly, and that the end of CP El Niño (La Niña) tend to be accompanied by the onset of canonical La Niña (El Niño). To test whether the out-of-phase configuration of the SST anomalies occurs more frequently in the latter period, we define the central Pacific SST anomalies index (CP_SST) as the SST anomalies averaged over $10^{\circ} \mathrm{S}-10^{\circ} \mathrm{N}, 170 \mathrm{E}^{\circ}-130^{\circ} \mathrm{W}$, which is marked in Fig. 10 . Figure 13 shows the scatter diagram of standardized $\mathrm{CP}_{-}$ SST in previous winter and the simultaneous summer Niño-3 index during 1979-2002 and 2003-17. Before 2003, 17 of 24 cases exhibit as in-phase configuration of these two indexes, consistent with the positive SST anomalies over the tropical central eastern Pacific in both previous winter and the following summer associated with the WNPSHI or EAJI (e.g., Figs. 9a,e). However, during the latter period, 10 out of 15 cases exhibit as out-of-phase configuration of these two indexes. These results confirm that the change in the features of SST anomalies over tropical central eastern Pacific may act as the background that favors the weakened WNPSH-EAJ relationship.

The analyses in this section indicate that the establishment of the WNPSH-EAJ relationship is associated with the decay of the canonical El Niño and the warm SST anomalies over the tropical Indian Ocean in 


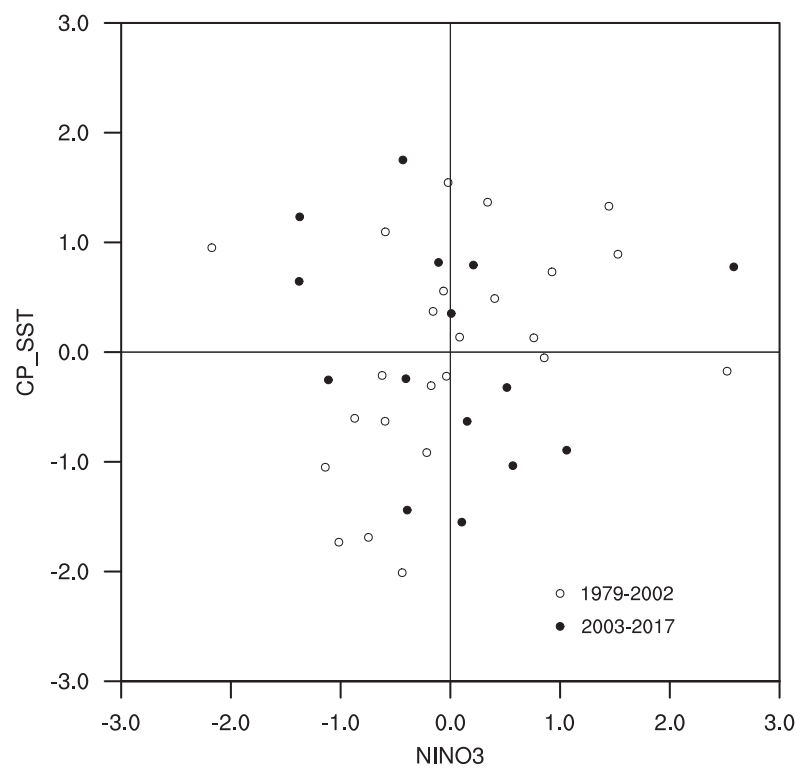

FIG. 13. Scatter diagrams of the standardized CP_SST index (see text for definition) in previous winter and the simultaneous summer Niño-3 index during 1979-2002 (hollow dots) and 2003-17 (solid dots), respectively.

simultaneous summer in the former period, consistent with previous studies. However, this widely believed association no longer exists during the latter period. Instead, the negative SST anomalies over the tropical central eastern Pacific in summer, in association with the decay of CP-like El Niño, begin to play a role. These SST anomalies tend to favor the westward extension of the WNPSH and the northward shift of the EAJ, leading to a weakened WNPSH-EAJ relationship. In addition to the decadal change in tropical SST anomalies associated with the WNPSHI and EAJI, we have also carefully examined the decadal changes in circulations in both lower and upper troposphere over the WNP-EA, including the intensity and meridional position of the EAJ, but failed in finding significant change in the circulation background (not shown).

\section{Conclusions and discussion}

There is a well-known meridional teleconnection pattern over the WNP-EA during summer, which is characterized by the zonally elongated circulation and precipitation anomalies with alternate signs in the meridional direction. Spanning the tropical and extratropical WNP-EA, this meridional teleconnection acts as a link between tropical forcings, such as ENSO, and climate anomalies over extratropical East Asia.

This study, however, found a breakdown of the meridional teleconnection since the early 2000s; more exactly, the tropical-extratropical connections associated with the meridional teleconnection pattern become absent after the early 2000s. For instance, as two components of the teleconnection, the westward extension (eastward retreat) of the WNP subtropical high (WNPSH) is closely related to the southward (northward) displacement of the East Asian westerly jet (EAJ) during 1979-2002, but this relationship is obscure during 2003-17. In addition, the well-known seesaw pattern in precipitation between the tropical WNP and subtropical WNP-EA, which is clear in the former period, is also absent in the latter period. Although the precipitation anomalies in the tropical WNP can induce significant WNPSH anomalies in both periods, the WNPSH anomalies can affect precipitation in the subtropical WNP-EA only in the former period, not in the latter period.

Further results indicate that the evolution of tropical SST anomalies associated with the components of the meridional teleconnection experiences a considerable decadal change. In the former period, the SST anomalies associated with the westward extension of the WNPSH and the southward displacement of the EAJ both exhibit as the decay of canonical El Niño, and there are significant positive anomalies over the tropical Indian Ocean in simultaneous summer, as previously well documented. However, in the latter period, the SST anomalies associated with the westward extension of the WNPSH exhibit as the decay of CP-like El Niño, rather than canonical El Niño, and correspondingly, SST anomalies in the following summer become significantly negative in the tropical central and eastern Pacific but very weak in the Indian Ocean. The negative SST anomalies in the tropical central and eastern Pacific in summer favor the northward displacement of the EAJ, and thus hinder the correspondence between the westward extension (eastward retreat) of the WNPSH and the northward (southward) displacement of the EAJ in the latter period.

The interaction between circulation and precipitation anomalies over the WNP-EA also plays a role in changing the WNPSH-EAJ relationship. In the former period, both the WNPSH and EAJ anomalies are significantly related to the precipitation anomalies along the East Asian summer rainband (i.e., in the subtropical WNP-EA), due to the impacts of circulations on subtropical precipitation and the positive feedback of the subtropical precipitation on circulations (e.g., $\mathrm{Lu}$ and Lin 2009). In the latter period, however, associated with the breakdown of the WNPSH-EAJ relationship, the WNPSH anomalies do not relate to the cyclonic or anticyclonic anomalies in the lower troposphere over the midlatitude WNP-EA, which are the lowertropospheric representation of the meridional displacement of the EAJ. The present results indicate 
(a) Former Period: Tropical-Extra Link Established

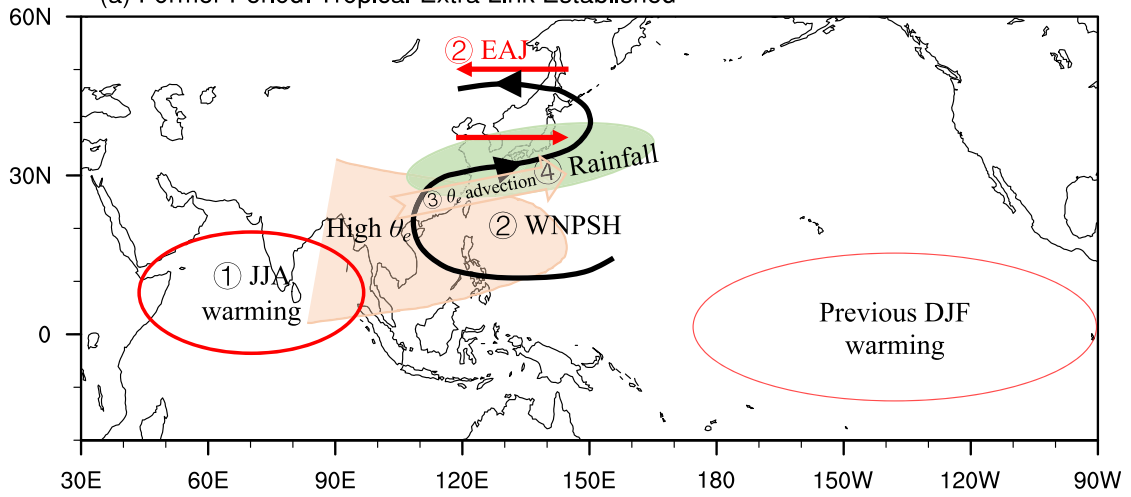

(b) Latter Period: Tropical-Extra Link Absent

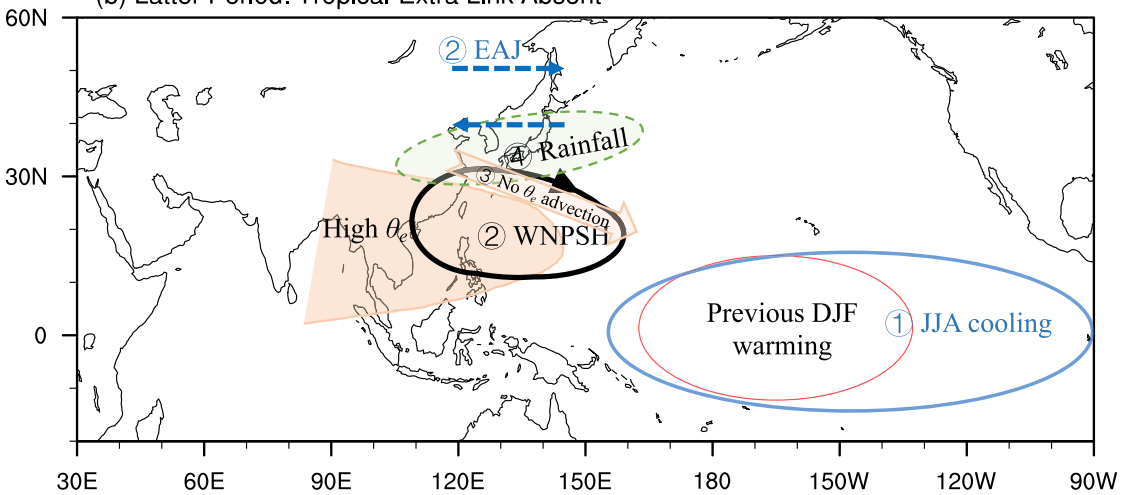

FIG. 14. Schematic diagram describing (a) the establishment of the teleconnection in the former period and (b) its breakdown in the latter period. In the former period shown in (a), the decay of canonical El Niño (red thin circle with "Previous DJF warming") and simultaneous summer tropical Indian Ocean warming (red thick circle with "(1) JJA warming") favor the westward extension of the WNPSH (black solid curve with "(2) WNPSH") and the southward shift of the EAJ (red arrows with "(2) EAJ"). The lower-tropospheric cyclonic anomaly in midlatitude East Asia (solid curve with black arrows under the red ones), associated with the southward shift of EAJ, results in westerly and southwesterly anomalies in the north flank of the WNPSH. These anomalies travel from high (orange shading with "High $\theta_{e}$ ") to low $\theta_{e}$ regions (orange arrow with "(3) $\theta_{e}$ advection") and favor enhanced subtropical rainfall (green oval with "(4) Rainfall”). In the latter period shown in (b), the cooler SSTs in tropical central eastern Pacific in summer (blue thick circle with "(1) JJA cooling"), in association with the decay of CP-like El Niño (red thin circle with "Previous DJF warming"), tends to result in the northward shift of EAJ (blue dashed arrows with "(2) EAJ"), which offsets the southward shift effect induced by the tropical WNP convection. As a result, the WNPSH-EAJ relationship is absent. The vague WNPSH-EAJ relationship leaves WNPSH as its own shape (black circle with "(2) WNPSH”), i.e., a typical anticyclonic anomaly over the WNP with northwesterly anomalies in its north flank (black arrow). The northwesterly anomalies in the north flank of the WNPSH cannot induce advection of climatological $\theta_{e}$ (orange arrow with "(3) No $\theta_{e}$ advection") and thus cannot induce the subtropical precipitation (green dashed circle with "(4) Rainfall"), resulting in the breakdown of the tropicalsubtropical seesaw pattern. In (b), dashed marks represent the absence of corresponding anomalies.

that without the midlatitude cyclonic or anticyclonic anomalies, the WNPSH anomalies exhibit as a typical anticyclonic anomaly over the WNP with northwesterly anomalies in its north flank. These northwesterly anomalies cannot induce subtropical WNP-EA rainfall, due to the lack of transportation of equivalent potential temperatures, and the tropical-subtropical seesaw pattern in precipitation is absent. Therefore, the impact of anomalous WNPSH on the subtropical WNP-EA precipitation, which has been widely believed previously, is not guaranteed and may be sensitive to extratropical circulation anomalies. 
Based on the present and previous results, we propose the following physical processes responsible for the decadal change of the meridional teleconnection in the early 2000s, as summarized schematically in Fig. 14. In the former period (Fig. 14a), the decay of canonical El Niño and tropical Indian Ocean warming in simultaneous summer favor the westward extension of the WNPSH and the southward shift of the EAJ; and these circulation anomalies are significantly related to the subtropical rainband, favoring the tropical-subtropical seesaw pattern in precipitation. By contrast, the latter period is featured with distinctly different processes (Fig. 14b). First, the negative SST anomalies in tropical central eastern Pacific in summer, in association with the decay of CP-like El Niño, results in the absence of the WNPSH-EAJ relationship. Second, the vague WNPSHEAJ relationship leaves WNPSH as its own shape (i.e., a typical anticyclonic anomaly over the WNP with northwesterly anomalies in its north flank). Third, the northwesterly anomalies cannot induce advection of climatological equivalent potential temperature and thus cannot induce the subtropical precipitation, resulting in the breakdown of the tropical-subtropical seesaw pattern.

The breakdown of the meridional teleconnection suggests a great challenge for seasonal forecast of East Asian climate in summer, which essentially depends on the tropical-extratropical coupling ( $\mathrm{Li}$ et al. 2012; Lu et al. 2012; Yim et al. 2016; Xing et al. 2017; Bett et al. 2018; Martin et al. 2020). Currently, climate models show a considerable capability in the seasonal forecast of the WNPSH (Li et al. 2012, 2014; Kosaka et al. 2013; Shin et al. 2019), but a weak predictability of the EAJ (Li and Lin 2015). It can be inferred that without the tropical-extratropical coupling over the WNP-EA, the extratropical circulation will be harder to be predicted, and thus further hinder the seasonal predictability of East Asian summer rainfall (Li et al. 2016; Lin et al. 2018). On the other hand, it would be interesting to further investigate the decadal changes in the relationship between the meridional teleconnection and tropical SSTs by analyzing the simulations of climate models, in order to better understand the potential diversity of such a relationship.

Acknowledgments. We thank the three anonymous reviewers for their insightful comments, which were helpful in improving the presentation. We also thank Dr. Fei Zheng and Dr. Zhongda Lin for their valuable comments. This work was supported by the National Natural Science Foundation of China (Grants 41905055 and 41721004), the Natural Science Foundation of Jiangsu Province (Grant BK20190500), and the Fundamental Research Funds for the Central Universities (B200202145).

\section{REFERENCES}

Adler, R. F., and Coauthors, 2003: The version-2 Global Precipitation Climatology Project (GPCP) monthly precipitation analysis (1979-present). J. Hydrometeor., 4, 1147-1167, https://doi.org/ 10.1175/1525-7541(2003)004<1147:TVGPCP >2.0.CO;2.

Ashok, K., S. K. Behera, S. A. Rao, H. Weng, and T. Yamagata, 2007: El Niño Modoki and its possible teleconnection. J. Geophys. Res., 112, C11007, https://doi.org/10.1029/2006JC003798.

Bett, P. E., and Coauthors, 2018: Seasonal forecasts of the summer 2016 Yangtze River basin rainfall. Adv. Atmos. Sci., 35, 918926, https://doi.org/10.1007/s00376-018-7210-y.

Bretherton, C. S., and A. H. Sobel, 2003: The Gill model and the weak temperature gradient approximation. J. Atmos. Sci., 60, 451460, https://doi.org/10.1175/1520-0469(2003)060<0451:TGMATW > 2.0.CO;2.

Chen, G., J. Lu, and D. M. W. Frierson, 2008: Phase speed spectra and the latitude of surface westerlies: Interannual variability and global warming trend. J. Climate, 21, 5942-5959, https:// doi.org/10.1175/2008JCLI2306.1.

Chen, T.-J. G., and C.-P. Chang, 1980: The structure and vorticity budget of an early summer monsoon through (mei-yu) over southeastern China and Japan. Mon. Wea. Rev., 108, 942-953, https://doi.org/10.1175/1520-0493(1980)108<0942:TSAVBO> 2.0.CO;2.

Dee, D. P., and Coauthors, 2011: The ERA-Interim reanalysis: Configuration and performance of the data assimilation system. Quart. J. Roy. Meteor. Soc., 137, 553-597, https://doi.org/ 10.1002/qj.828.

Ding, Y., 1992: Summer monsoon rainfalls in China. J. Meteor. Soc. Japan, 70, 373-396, https://doi.org/10.2151/jmsj1965.70.1B_ 373.

Du, Y., T. Li, Z. Xie, and Z. Zhu, 2016: Interannual variability of the Asian subtropical westerly jet in boreal summer and associated with circulation and SST anomalies. Climate Dyn., 46, 2673-2688, https://doi.org/10.1007/s00382-015-2723-x.

Feng, J., W. Chen, C. Y. Tam, and W. Zhou, 2011: Different impacts of El Niño and El Niño Modoki on China rainfall in the decaying phases. Int. J. Climatol., 31, 2091-2101, https:// doi.org/10.1002/JOC. 2217.

Gao, C., and Coauthors, 2019: Land-atmosphere interaction over the Indo-China Peninsula during spring and its effect on the following summer climate over the Yangtze River basin. Climate Dyn., 53, 6181-6198, https://doi.org/10.1007/S00382019-04922-X.

Gong, H., L. Wang, W. Chen, R. Wu, G. Huang, and D. Nath, 2018: Diversity of the Pacific-Japan pattern among CMIP5 models: Role of SST anomalies and atmospheric mean flow. J. Climate, 31, 6857-6877, https://doi.org/10.1175/JCLI-D-17-0541.1.

Gong, T., S. B. Feldstein, and D. Luo, 2010: The impact of ENSO on wave breaking and southern annular mode events. J. Atmos. Sci., 67, 2854-2870, https://doi.org/10.1175/2010JAS3311.1.

$\mathrm{He}, \mathrm{Z}$., and R. Wu, 2018: Change in coherence of interannual variability of summer rainfall over the western Pacific around the early 2000s: Role of Indo-Pacific ocean forcing. J. Climate, 31, 3525-3538, https://doi.org/10.1175/JCLI-D-17-0687.1.

Held, I. M., and A. Y. Hou, 1980: Nonlinear axially symmetric circulations in a nearly inviscid atmosphere. J. Atmos. Sci., 37, 515-533, https:// doi.org/10.1175/1520-0469(1980)037<0515:NASCIA >2.0.CO;2.

Hong, X., and R. Lu, 2016: The meridional displacement of the summer Asian jet, Silk Road Pattern, and tropical SST anomalies. J. Climate, 29, 3753-3766, https://doi.org/10.1175/ JCLI-D-15-0541.1. 
Hu, Z.-Z., A. Kumar, H.-L. Ren, H. Wang, M. L'Heureux, and F.-F. Jin, 2013: Weakened interannual variability in the tropical Pacific Ocean since 2000. J. Climate, 26, 2601-2613, https:// doi.org/10.1175/JCLI-D-12-00265.1.

Huang, G., K. Hu, and S. Xie, 2010: Strengthening of tropical Indian Ocean teleconnection to the northwest Pacific since the mid-1970s: An atmospheric GCM study. J. Climate, 23, 5294 5304, https://doi.org/10.1175/2010JCLI3577.1.

$\longrightarrow,-$ X X. Qu, W. Tao, S. Yao, G. Zhao, and W. Jiang, 2016: A review about Indian Ocean basin mode and its impacts on East Asian summer climate (in Chinese). Chin. J. Atmos. Sci., 40, 121-130.

Huang, R., and Y. Wu, 1989: The influence of ENSO on the summer climate change in China and its mechanism. Adv. Atmos. Sci., 6, 21-32, https://doi.org/10.1007/bf02656915.

_ _ and F. Sun, 1992: Impacts of the tropical western Pacific on the East Asia summer monsoon. J. Meteor. Soc. Japan, 70, 243-256, https://doi.org/10.2151/jmsj1965.70.1B_243.

- J. Chen, L. Wang, and Z. Lin, 2012: Characteristics, processes, and causes of the spatio-temporal variabilities of the East Asian monsoon system. Adv. Atmos. Sci., 29, 910-942, https://doi.org/10.1007/S00376-012-2015-X.

Huang, Y., B. Wang, X. Li, and H. Wang, 2018: Changes in the influence of the western Pacific subtropical high on Asian summer monsoon rainfall in the late 1990s. Climate Dyn., 51, 443-455, https://doi.org/10.1007/s00382-017-3933-1.

Huang, Z., W. Zhang, X. Geng, and F. Jin, 2020: Recent shift in the state of the western Pacific subtropical high due to ENSO change. J. Climate, 33, 229-241, https://doi.org/10.1175/JCLID-18-0873.1.

Huffman, G. J., and Coauthors, 1997: The Global Precipitation Climatology Project (GPCP) combined precipitation dataset. Bull. Amer. Meteor. Soc., 78, 5-20, https://doi.org/10.1175/ 1520-0477(1997)078<0005:TGPCPG $>2.0 . C O ; 2$.

Jiang, W., G. Huang, P. Huang, R. Wu, K. Hu, and W. Chen, 2019: Northwest Pacific anticyclonic anomalies during post-El Niño summers determined by the pace of El Niño decay. J. Climate, 32, 3487-3503, https://doi.org/10.1175/JCLI-D-18-0793.1.

Kao, H.-Y., and J.-Y. Yu, 2009: Contrasting eastern-Pacific and central-Pacific types of ENSO. J. Climate, 22, 615-632, https:// doi.org/10.1175/2008JCLI2309.1.

Kim, J.-E., S.-W. Yeh, and S.-Y. Hong, 2009: Two types of strong northeast Asian summer monsoon. J. Climate, 22, 4406-4417, https://doi.org/10.1175/2009JCLI2434.1.

Kosaka, Y., and H. Nakamura, 2006: Structure and dynamics of the summertime Pacific-Japan teleconnection pattern. Quart. J. Roy. Meteor. Soc., 132, 2009-2030, https://doi.org/10.1256/ qj.05.204.

- and - 2010: Mechanisms of meridional teleconnection observed between a summer monsoon system and a subtropical anticyclone. Part I: The Pacific-Japan pattern. J. Climate, 23, 5085-5108, https://doi.org/10.1175/2010JCLI3413.1.

_ S.-P. Xie, and H. Nakamura, 2011: Dynamics of interannual variability in summer precipitation over East Asia. J. Climate, 24, 5435-5453, https://doi.org/10.1175/2011JCLI4099.1.

,,-- N.-C. Lau, and G. A. Vecchi, 2013: Origin of seasonal predictability for summer climate over the northwestern Pacific. Proc. Natl. Acad. Sci. USA, 110, 7574-7579, https:// doi.org/10.1073/pnas.1215582110.

Kubota, H., Y. Kosaka, and S.-P. Xie, 2016: A 117-year long index of the Pacific-Japan pattern with application to interdecadal variability. Int. J. Climatol., 36, 1575-1589, https://doi.org/ 10.1002/joc.4441.
Kwon, M., J.-G. Jhun, B. Wang, S.-I. An, and J.-S. Kug, 2005: Decadal change in relationship between East Asian and WNP summer monsoons. Geophys. Res. Lett., 32, L16709, https:// doi.org/10.1029/2005GL023026.

Lau, K.-M., K.-M. Kim, and S. Yang, 2000: Dynamical and boundary forcing characteristics of regional components of the Asian summer monsoon. J. Climate, 13, 2461-2482, https:// doi.org/10.1175/1520-0442(2000)013<2461:DABFCO >2.0. $\mathrm{CO} ; 2$.

Lau, N.-C., and M. J. Nath, 2006: ENSO modulation of the interannual and intraseasonal variability of the East Asian monsoon-A model study. J. Climate, 19, 4508-4530, https:// doi.org/10.1175/JCLI3878.1.

Lee, E.-J., S.-W. Yeh, J.-G. Jhun, and B.-K. Moon, 2006: Seasonal change in anomalous WNPSH associated with the strong East Asian summer monsoon. Geophys. Res. Lett., 33, L21702, https://doi.org/10.1029/2006GL027474.

Li, C., and Z. Lin, 2015: Predictability of the summer East Asian upper-tropospheric westerly jet in ENSEMBLES multi-model forecasts. Adv. Atmos. Sci., 32, 1669-1682, https://doi.org/ 10.1007/s00376-015-5057-z.

— R. Ru, and B. Dong, 2012: Predictability of the western North Pacific summer climate demonstrated by the coupled models of ENSEMBLES. Climate Dyn., 39, 329-346, https://doi.org/ 10.1007/s00382-011-1274-z.

,-- , and -2014 : Predictability of the western North Pacific summer climate associated with different ENSO phases by ENSEMBLES multi-model seasonal forecasts. Climate Dyn., 43, 1829-1845, https://doi.org/10.1007/s00382-013-2010-7.

- and Coauthors, 2016: Skillful seasonal prediction of Yangtze River valley summer rainfall. Environ. Res. Lett., 11, 094002, https://doi.org/10.1088/1748-9326/11/9/094002.

Li, H., S. He, K. Fan, and H. Wang, 2019: Relationship between the onset date of the Meiyu and the South Asian anticyclone in April and the related mechanisms. Climate Dyn., 52, 209-226, https://doi.org/10.1007/s00382-018-4131-5.

Li, L., and Y. Zhang, 2014: Effects of different configurations of the East Asian subtropical and polar front jets on precipitation during the mei-yu season. J. Climate, 27, 6660-6672, https:// doi.org/10.1175/JCLI-D-14-00021.1.

Li, S., J. Lu, G. Huang, and K. Hu, 2008: Tropical Indian Ocean basin warming and East Asian summer monsoon: A multiple AGCM study. J. Climate, 21, 6080-6088, https://doi.org/ 10.1175/2008JCLI2433.1.

Li, T., B. Wang, B. Wu, T. Zhou, C.-P. Chang, and R. Zhang, 2017: Theories on formation of an anomalous anticyclone in western North Pacific during El Niño: A review. J. Meteor. Res., 31, 987-1006, https://doi.org/10.1007/s13351-017-7147-6.

Li, X., and R. Lu, 2017: Extratropical factors affecting the variability in summer precipitation over the Yangtze River basin, China. J. Climate, 30, 8357-8374, https://doi.org/10.1175/JCLI-D-16-0282.1. , and — 2018: Subseasonal change in the seesaw pattern of precipitation between the Yangtze River basin and the tropical western North Pacific during summer. Adv. Atmos. Sci., 35, 1231-1242, https://doi.org/10.1007/s00376-018-7304-6.

, C. Li, J. Ling, and Y. Tan, 2015: The relationship between contiguous El Niño and La Niña revealed by self-organizing maps. J. Climate, 28, 8118-8134, https://doi.org/10.1175/JCLID-15-0123.1.

, G. Gollan, R. J. Greatbatch, and R. Lu, 2019: Impact of the MJO on the interannual variation of the Pacific-Japan mode of the East Asian summer monsoon. Climate Dyn., 52, 34893501, https://doi.org/10.1007/s00382-018-4328-7. 
Liang, X.-Z., and W.-C. Wang, 1998: Associations between China monsoon rainfall and tropospheric jets. Quart. J. Roy. Meteor. Soc., 124, 2597-2623, https://doi.org/10.1002/qj.49712455204.

Lin, X., C. Li, R. Lu, and A. A. Scaife, 2018: Predictable and unpredictable components of the summer East Asia-Pacific teleconnection pattern. Adv. Atmos. Sci., 35, 1372-1380, https://doi.org/10.1007/s00376-018-7305-5.

Lin, Z., 2010: Relationship between meridional displacement of the monthly East Asian jet stream in the summer and sea surface temperature in the tropical central and eastern Pacific. Atmos. Oceanic Sci. Lett., 3, 40-44, https://doi.org/10.1080/16742834.2010. 11446840.

— in the following early summer. Adv. Atmos. Sci., 26, 333-342, https://doi.org/10.1007/s00376-009-0333-4.

,-- , and W. Zhou, 2010: Change in early-summer meridional teleconnection over the western North Pacific and East Asia around the late 1970s. Int. J. Climatol., 30, 2195-2204, https://doi.org/10.1002/joc.2038.

Lu, J., G. Chen, and D. M. W. Frierson, 2008: Response of the zonal mean atmospheric circulation to El Niño versus global warming. J. Climate, 21, 5835-5851, https://doi.org/10.1175/ 2008JCLI2200.1.

Lu, R., 2001: Atmospheric circulations and sea surface temperatures related to the convection over the western Pacific warm pool on the interannual scale. Adv. Atmos. Sci., 18, 270-282, https://doi.org/10.1007/s00376-001-0019-z.

_- 2004: Associations among the components of the East Asian summer monsoon system in the meridional direction. J. Meteor. Soc. Japan, 82, 155-165, https://doi.org/10.2151/jmsj.82.155.

_ 2005: Interannual variation of North China rainfall in rainy season and SSTs in the equatorial eastern Pacific. Chin. Sci. Bull., 50, 2069-2073, https://doi.org/10.1360/04wd0271.

— , and Z. Lin, 2009: Role of subtropical precipitation anomalies in maintaining the summertime meridional teleconnection over the western North Pacific and East Asia. J. Climate, 22, 2058-2072, https://doi.org/10.1175/2008JCLI2444.1.

—_, and S. Lu, 2015: Asymmetric relationship between Indian Ocean SST and the western North Pacific summer monsoon. J. Climate, 28, 1383-1395, https://doi.org/10.1175/JCLI-D-1400289.1.

— C. Li, S.-H. Yang, and B. Dong, 2012: The coupled model predictability of the western North Pacific summer monsoon with different leading times. Atmos. Oceanic Sci. Lett., 5, 219224, https://doi.org/10.1080/16742834.2012.11447000.

Martin, G. M., N. J. Dunstone, A. A. Scaife, and P. E. Bett, 2020: Predicting June mean rainfall in the middle/lower Yangtze River basin. Adv. Atmos. Sci., 37, 29-41, https://doi.org/ 10.1007/s00376-019-9051-8.

McPhaden, M. J., 2012: A 21st century shift in the relationship between ENSO SST and warm water volume anomalies. Geophys. Res. Lett., 39, L09706, https://doi.org/10.1029/2012GL051826.

Ninomiya, K., 1984: Characteristics of Baiu front as a predominant subtropical front in the summer Northern Hemisphere. J. Meteor. Soc. Japan, 62, 880-894, https://doi.org/10.2151/jmsj1965.62.6_ 880.

— , and Y. Shibagaki, 2007: Multi-scale features of the Meiyu-Baiu front and associated precipitation systems. J. Meteor. Soc. Japan, 85B, 103-122, https://doi.org/10.2151/jmsj.85B.103.

Nitta, T., 1987: Convective activities in the tropical western Pacific and their impact on the Northern Hemisphere summer circulation. J. Meteor. Soc. Japan, 65, 373-390, https://doi.org/ 10.2151/jmsj1965.65.3_373.
Park, H.-S., B. R. Lintner, W. R. Boos, and K.-H. Seo, 2015: The effect of midlatitude transient eddies on monsoonal southerlies over eastern China. J. Climate, 28, 8450-8465, https:// doi.org/10.1175/JCLI-D-15-0133.1.

Qu, X., and G. Huang, 2011: Impacts of tropical Indian Ocean SST on the meridional displacement of East Asian jet in boreal summer. Int. J. Climatol., 32, 2073-2080, https://doi.org/ $10.1002 /$ joc. 2378

Rodionov, S. N., 2004: A sequential algorithm for testing climate regime shifts. Geophys. Res. Lett., 31, L09204, https://doi.org/ 10.1029/2004GL019448.

_ 2006: Use of prewhitening in climate regime shift detection. Geophys. Res. Lett., 33, L12707, https://doi.org/10.1029/2006 GL025904.

Seager, R., N. Harnik, Y. Kushnir, W. A. Robinson, and J. Miller, 2003: Mechanisms of hemispherically symmetric climate variability. J. Climate, 16, 2960-2978, https://doi.org/10.1175/ 1520-0442(2003)016<2960:MOHSCV > 2.0.CO;2.

Shaman, J., and E. Tziperman, 2007: The summertime ENSONorth African-Asian jet teleconnection and implications for the Indian monsoons. Geophys. Res. Lett., 34, L11702, https:// doi.org/10.1029/2006GL029143.

Shin, C.-S., B. Huang, J. Zhu, L. Marx, and J. L. Kinter, 2019: Improved seasonal predictive skill and enhanced predictability of the Asian summer monsoon rainfall following ENSO events in NCEP CFSv2 hindcasts. Climate Dyn., 52, 30793098, https://doi.org/10.1007/s00382-018-4316-y.

Sun, L., G. Chen, and J. Lu, 2013: Sensitivities and mechanisms of the zonal mean atmospheric circulation response to tropical warming. J. Atmos. Sci., 70, 2487-2504, https://doi.org/10.1175/ JAS-D-12-0298.1.

Sun, X., R. J. Greatbatch, W. Park, and M. Latif, 2010: Two major modes of variability of the East Asian summer monsoon. Quart. J. Roy. Meteor. Soc., 136, 829-841, https://doi.org/10.1002/qj.635.

_- Y. Xu, Z. Zhang, and X.-Q. Yang, 2019: The tropical and extratropical-origin summer meridional teleconnections over east Asia. Climate Dyn., 53, 721-735, https://doi.org/10.1007/ s00382-018-04610-2.

Terao, T., and T. Kubota, 2005: East-west SST contrast over the tropical oceans and the post El Niño western North Pacific summer monsoon. Geophys. Res. Lett., 32, L15706, https:// doi.org/10.1029/2005GL023010.

Wang, B., R. Wu, and X. Fu, 2000: Pacific-East Asian teleconnection: How does ENSO affect East Asian climate? J. Climate, 13, 15171536, https://doi.org/10.1175/1520-0442(2000)013<1517:PEATHD> 2.0.CO;2.

_,- , and K.-M. Lau, 2001: Interannual variability of the Asian summer monsoon: Contrasts between the Indian and the western North Pacific-East Asian monsoons. J. Climate, 14, 4073-4090, https://doi.org/10.1175/1520-0442(2001)014<4073:IVOTAS $>2.0$. $\mathrm{CO} ; 2$.

_ B. Xiang, and J. Y. Lee, 2013: Subtropical high predictability establishes a promising way for monsoon and tropical storm predictions. Proc. Natl. Acad. Sci. USA, 110, 2718-2722, https://doi.org/10.1073/pnas.1214626110.

Wang, S., H. Zuo, S. Zhao, J. Zhang, and S. Lu, 2018: How East Asian westerly jet's meridional position affects the summer rainfall in Yangtze-Huaihe River valley? Climate Dyn., 51, 4109-4121, https://doi.org/10.1007/s00382-017-3591-3.

, - - Y. Yin, J. Wang, and X. Ma, 2019: Asymmetric impact of East Asian jet's variation on midsummer rainfall in North China and Yangtze River valley. Climate Dyn., 53, 6199-6213, https://doi.org/10.1007/s00382-019-04923-w. 
Wen, C., A. Kumar, Y. Xue, and M. J. McPhaden, 2014: Changes in tropical Pacific thermocline depth and their relationship to ENSO after 1999. J. Climate, 27, 7230-7249, https://doi.org/ 10.1175/JCLI-D-13-00518.1.

Wu, M., and L. Wang, 2019: Enhanced correlation between ENSO and western North Pacific monsoon during boreal summer around the 1990s. Atmos. Oceanic Sci. Lett., 12, 376-384, https://doi.org/10.1080/16742834.2019.1641397.

Wu, R., and B. Wang, 2001: Multi-stage onset of the summer monsoon over the western North Pacific. Climate Dyn., 17, 277-289, https://doi.org/10.1007/s003820000118.

— monsoon-ENSO relationship between 1962-77 and 1978-93 J. Climate, 15, 3266-3279, https://doi.org/10.1175/1520-0442(2002) 015<3266:ACOTEA > 2.0.CO;2.

Xiang, B.-Q., B. Wang, and T. Li, 2013: A new paradigm for the predominance of standing central Pacific warming after the late 1990s. Climate Dyn., 41, 327-340, https://doi.org/10.1007/ s00382-012-1427-8.

Xie, S.-P., K. Hu, J. Hafner, H. Tokinaga, Y. Du, G. Huang, and T. Sampe, 2009: Indian Ocean capacitor effect on Indo-western Pacific climate during the summer following El Niño. J. Climate, 22, 730-747, https://doi.org/10.1175/2008JCLI2544.1.

_ , Y. Kosaka, Y. Du, K. Hu, J. S. Chowdary, and G. Huang, 2016: Indo-western Pacific Ocean capacitor and coherent climate anomalies in post-ENSO summer: A review. Adv. Atmos. Sci., 33, 411-432, https://doi.org/10.1007/s00376-015-5192-6.

Xing, W., B. Wang, S.-Y. Yim, and K.-J. Ha, 2017: Predictable patterns of the May-June rainfall anomaly over east Asia. J. Geophys. Res. Atmos., 122, 2203-2217, https://doi.org/ 10.1002/2016JD025856.

Xu, P., L. Wang, W. Chen, J. Feng, and Y. Liu, 2019: Structural changes in the Pacific-Japan pattern in the late 1990s. J. Climate, 32, 607-621, https://doi.org/10.1175/JCLI-D-18-0123.1.

Xuan, S., Q. Zhang, and S. Sun, 2011: Anomalous midsummer rainfall in Yangtze River-Huaihe River valleys and its association with the East Asia westerly jet. Adv. Atmos. Sci., 28, 387-397, https://doi.org/10.1007/s00376-010-0111-3.
Yan, Y., C. Li, and R. Lu, 2019: Meridional displacement of the East Asian upper-tropospheric westerly jet and its relationship with the East Asian summer rainfall in CMIP5 simulations. Adv. Atmos. Sci., 36, 1203-1216, https://doi.org/10.1007/s00376-0199066-1.

Yang, J., Q. Liu, S.-P. Xie, Z. Liu, and L. Wu, 2007: Impact of the Indian Ocean SST basin mode on the Asian summer monsoon. Geophys. Res. Lett., 34, L02708, https://doi.org/10.1029/2006GL028571.

Yeh, S.-W., J.-S. Kug, B. Dewitte, M.-H. Kwon, B. P. Kirtman, and F.-F. Jin, 2009: El Niño in a changing climate. Nature, 461, 511-514, https://doi.org/10.1038/nature08316.

Yim, S.-Y., S.-W. Yeh, R. Wu, and J.-G. Jhun, 2008a: The influence of ENSO on decadal variations in the relationship between the East Asian and western North Pacific summer monsoons. J. Climate, 21, 3165-3179, https://doi.org/10.1175/2007JCLI1948.1.

_ J.-G. Jhun, and S.-W. Yeh, 2008b: Decadal change in the relationship between East Asian-western North Pacific summer monsoons and ENSO in the mid-1990s. Geophys. Res. Lett., 35, L20711, https://doi.org/10.1029/2008GL035751.

_ - B. Wang, and W. Xing, 2016: Peak-summer East Asian rainfall predictability and prediction. Part II: Extratropical East Asia. Climate Dyn., 47, 15-30, https://doi.org/10.1007/ s00382-015-2849-x.

Yu, J.-Y., P.-K. Kao, H. Paek, H.-H. Hsu, C.-W. Hung, M.-M. Lu, and S.-I. An, 2015: Linking emergence of the central Pacific El Niño to the Atlantic multidecadal oscillation. J. Climate, 28, 651-662, https://doi.org/10.1175/JCLI-D-14-00347.1.

Yun, K.-S., S.-W. Yeh, and K.-J. Ha, 2013: Distinct impact of tropical SSTs on summer North Pacific high and western North Pacific subtropical high. J. Geophys. Res. Atmos., 118, 4107-4116, https://doi.org/10.1002/JGRD.50253.

Zhou, T., and R. Yu, 2005: Atmospheric water vapor transport associated with typical anomalous summer rainfall patterns in China. J. Geophys. Res., 110, D08104, https://doi.org/10.1029/ 2004JD005413.

Zhu, Q., J. Lin, S. Shou, and D. Tang, 2000: Principles and Methods of Synoptic Meteorology (in Chinese). China Meteorological Press, 649 pp. 